\title{
Chitosan-based scaffolds for bone tissue engineering
}

\author{
Sheeny Lan Levengood and Miqin Zhang ${ }^{*}$ \\ Department of Materials Science \& Engineering, University of Washington, Seattle, WA 98195 \\ USA
}

\section{Abstract}

Bone defects requiring grafts to promote healing are frequently occurring and costly problems in health care. Chitosan, a biodegradable, naturally occurring polymer, has drawn considerable attention in recent years as scaffolding material in tissue engineering and regenerative medicine. Chitosan is especially attractive as a bone scaffold material because it supports the attachment and proliferation of osteoblast cells as well as formation of mineralized bone matrix. In this review, we discuss the fundamentals of bone tissue engineering and the unique properties of chitosan as a scaffolding material to treat bone defects for hard tissue regeneration. We present the common methods for fabrication and characterization of chitosan scaffolds, and discuss the influence of material preparation and addition of polymeric or ceramic components or biomolecules on chitosan scaffold properties such as mechanical strength, structural integrity, and functional bone regeneration. Finally, we highlight recent advances in development of chitosan-based scaffolds with enhanced bone regeneration capability.

\section{Introduction}

Unlike many other tissues, bone has the remarkable ability to regenerate when damaged. In many cases, bone fractures can be immobilized to allow for spontaneous healing over time. However, when bone defects are large enough or critical-sized, they cannot regenerate via normal physiological processes and require intervention in the form of bone grafts. This is often the case for segmental defects, fracture non-unions, and traumatic fractures where minimal tissue integrity remains in the defect site. The clinical standards for bone grafting are autografts, harvested from a secondary site in the patient, and allografts, harvested from cadavers and sterilized prior to use. Often additional materials such as pins, plates and bone fillers are needed to immobilize the grafts.

Bone grafts and their companion materials constitute a billion dollar industry as upwards of 1.5 million grafts are placed annually in the United States. ${ }^{1,2}$ The worldwide incidence of bone disorders and conditions is expected to double by 2020, especially in populations where aging is coupled with increased obesity and poor physical activity. ${ }^{3}$ While the standard approaches generally result in successful defect repair, complications such as donor site morbidity or disease transmission often arise, which demands the investigation of suitable alternatives. ${ }^{4-7}$ Bone tissue engineering strategies offer promising alternatives to 
autografts and allografts by utilizing synthetic grafts to guide tissue regeneration. A synthetic graft, commonly known as a scaffold, should act as filler within the defect site and promote bone regeneration. At minimum, a synthetic bone scaffold should be 1) osteoconductive to facilitate bone formation on its surface and 2) highly porous to allow for nutrient and waste transport, neovascularization/angiogenesis and bone ingrowth. In addition to these minimum requirements, a scaffold should have adequate mechanical strength to support bone ingrowth at the site of implantation and maintain structural integrity during in vivo tissue remodeling and it should degrade over time in concert with bone regeneration. Scaffolds are often combined with cells and/or growth factors to promote osteoinductivity and aid in the tissue regeneration process.

Different classes of materials have been utilized for scaffold fabrication including a variety of ceramics and polymers. Synthetic calcium phosphate-based ceramics such as biphasic calcium phosphate, $\beta$-tricalcium phosphate, and hydroxyapatite are popular scaffolding materials because their chemical structures are similar to the mineral phase of bone. Other ceramics utilized for bone tissue engineering include bioactive glasses, glass-ceramics, silica and titania. ${ }^{8-12}$ Both synthetic and natural polymers have been investigated as bone scaffold materials. Synthetic polymers of interest include polyesters such as polycaprolactone (PCL) ${ }^{13,} 14$ poly(lactic acid) (PLA), poly(glycolic acid) (PGA) and poly(latic-co-glycolic acid) PLGA. ${ }^{15,16}$ Natural polymers investigated for this application include polysaccharides such as alginate and chitosan, proteins such as collagen, gelatin and silk fibroin, and glycosaminoglycans such as chondroitin sulfate and hyaluronic acid. ${ }^{17}$ Some of natural and synthetic polymeric scaffolds utilized for bone tissue engineering can be found in Table 1.

Chitosan, a naturally occurring polymer, is a highly versatile biomaterial. Unlike natural polymers derived from costly mammalian proteins, chitosan evokes minimal foreign-body response and fibrous encapsulation. It is derived from the shells of crustaceans, a natural and renewable source. ${ }^{18-21}$ Contrary to many synthetic polymers, chitosan has a hydrophilic surface that promotes cell adhesion and proliferation and its degradation products are nontoxic. Chitosan is an especially attractive as a bone scaffold material as it supports the attachment and proliferation of bone-forming osteoblast cells as well as formation of mineralized bone matrix in vitro. ${ }^{22}$ In addition, studies have shown that modified chitosan scaffolds exhibit osteoconductivity in vivo in surgically created bone defects. ${ }^{23}$ Very few compounds are classified as bioactive, biodegradable and osteoconductive; chitosan and hydroxyapatite are among the most promising biomaterials utilized for bone tissue engineering. ${ }^{24}$ Significantly, chitosan is a facile material that can be processed in multiple ways to produce a variety of 3-dimensional scaffolds with different pore structures for use in bone tissue engineering. It can also be combined with a variety of materials including ceramics and polymers to yield composite scaffolds with superior mechanical and biological properties.

Here we discuss some fundamentals in bone tissue engineering and recent advances in the fabrication of chitosan and composite chitosan scaffolds for non-load-bearing bone tissue engineering applications. We begin with a discussion of common methods used for fabrication of porous scaffolds, followed by techniques that combine polymers or ceramics with chitosan to yield composite scaffolds. We then discuss how the inclusion of these 
constituents improves scaffold mechanical and biological properties. Finally we review some recent advances in chitosan-based bone scaffold technology including the in vivo evaluation of scaffold-supported bone regeneration using animal models of critical-sized bone defects.

\section{Overview of bone biology}

Bone is a multi-scale, hierarchically structured composite tissue (Figure 1) that plays multiple physiological roles. ${ }^{25}$ Bone itself consists mainly of collagen fibers and crystals of an apatite of calcium and phosphate where the apatite crystals are formed as slender needles within and among the collagen fibers. Structurally, mineralized bone is divided into two categories based on density. Cortical tissue is very dense and constitutes the outer surface of bones whereas cancellous tissue is highly porous. Cancellous tissue is located in the interior of bones and contains bone marrow. Bone provides the body with scaffolding as well as a compartmental structure. It transmits forces or motion from one part of the body to another and it acts as a mineral reservoir. Bone is a dynamic tissue that consistently undergoes modeling and remodeling processes of resorption and regeneration in response to mechanical and metabolic changes. The primary cells that dictate bone formation and remodeling are osteoblasts, osteoclasts and osteocytes. Osteoblasts, derived from mesenchymal stem cells, function to synthesize osteoid and regulate mineralization. Osteoid, an unmineralized matrix, is composed mostly (94\%) of type I collagen, but also contains signaling proteins, such as growth factors, bone-specific non-collagenous proteins and proteoglycans. ${ }^{26}$ During bone formation, the unmineralized matrix is calcified with a nonstoichiometric carbonated apatite. This bone mineral is similar to synthetic and stoichiometric hydroxyapatite and has a plate-like structure (2-6 nm thick, 30-50 nm wide and $60-100 \mathrm{~nm}$ long). ${ }^{27,} 28$ While the mineralization process is not well understood, it appears to involve the budding of matrix vesicles from osteoblasts that contain a limited amount of pre-formed mineral crystals. These mineral crystals are released and serve as templates for homogenous nucleation of additional mineral crystals utilizing calcium and phosphate ions present in the extracellular fluid. ${ }^{29}$ When mineralization is complete, calcified bone is composed of approximately $25 \%$ organic matrix, $5 \%$ water and $70 \%$ inorganic mineral. ${ }^{26}$ Osteoblasts that become trapped within mineralized matrix further differentiate into osteocytes. Osteocytes are capable of perceiving energy associated with mechanical loading and translating that energy into a biological response involving bone resorption and regeneration, ${ }^{30}$ a property known as mechanotransduction. Osteocytes form a cellular network by extending dendritic processes through small canals or canaliculae and these processes allow the cells to act as mechanosensors. As the predominant cell type, osteocytes are thought to direct remodeling activities through the dispersal of paracrine signals to other osteogenic cells. ${ }^{31}$ Finally, osteoclasts, derived from macrophages, are the cells that resorb mineralized bone by forming a tight seal with their apical membrane and secreting lytic enzymes. ${ }^{26}$ These bone cells work in concert to maintain the integrity of healthy bone tissue and to regenerate bone that is damaged due to trauma or disease. In the case of critical-sized defects, which are too large to regenerate based on normal remodeling processes, bone grafts are needed to facilitate healing. 


\section{The bone tissue engineering approach}

While many materials are used in treatment of bone defects, such as metallic pins and screws and ceramic-based particulate bone fillers, there is a need for bulk synthetic grafts as alternatives to autogenous and allogeneic bone grafts. There are a few basic requirements for materials as bone scaffolds. The scaffold material must be osteoconductive, a term referring to the ability to recruit osteogenic cells, support their migration and serve as a template for newly forming bone. ${ }^{32,33}$ The scaffold must be highly porous yielding a structure that can provide space for cellular infiltration and attachment, diffusion of nutrients, oxygen and waste as well as neovascularization and bone ingrowth. A porous scaffold with sufficient porosity should be highly interconnected with an optimal pore size in the range of 200-600 $\mu \mathrm{m} .{ }^{34}$ In addition to this macroporosity requirement, microstructural features in terms of microporosity or surface roughness are also preferable as they may facilitate cell-scaffold interactions. ${ }^{35,36}$ Mechanical properties are also an important consideration in scaffold design and must be balanced against scaffold porosity as the two properties are intimately related. Scaffold strength must attain a minimum level in the case of non-load-bearing defects, and this strength should be defined based on maintenance of scaffold structural integrity during and following placement in a defect site. For most studies on polymer-based scaffolds the target strength is compressive strength in the range of cancellous bone, which is generally reported as 1-12 MPa (Table 2). ${ }^{37-39}$ Most studies involving chitosan-based scaffolds report the compressive modulus, which for human bone is generally 100-500 MPa. ${ }^{38,40}$ Mechanical properties are also closely related to scaffold degradation and ideally, the degradation rate should be tuned to match bone ingrowth so that regenerated bone continuously replaces the scaffold material. Methods utilized to fabricated porous scaffolds are described in detail below, but all afford a degree of control over the pore size and overall porosity. For example using the phase separation and lyophilization or freeze gelation methods, scaffold pore size decreases as the freezing temperature utilized to induce phase separation of chitosan decreases. ${ }^{41}$ When using the particulate leaching method to generate porosity, the smaller the porogen diameter, the smaller the resultant pores and lower the overall scaffold porosity. ${ }^{42}$ Correspondingly, decreasing the porogen concentration decreases the overall scaffold porosity. It is well documented that the scaffold porosity and mechanical properties are intimately related. ${ }^{20,43,44}$ The compressive strength of scaffolds tends to increase as pore size and overall porosity decreases. This is due to an increase in overall scaffold density and pore wall thickness, whereas larger and more interconnected pores mean a higher scaffold void volume and thus lower mechanical strength. The degradation rate of a scaffold is also intimately related to mechanical strength as the scaffold strength decreases in concert with degradation. ${ }^{45}$ The scaffold degradation rate is highly dependent on the scaffold material, and the properties of chitosan such as molecular weight and degree of deacetylation that affect the degradation rate are discussed in more detail below.

Synthetic grafts made of polymers and/or ceramics are often combined with biologics such as mesenchymal stem cells (MSCs) and/or growth factors to yield tissue engineering constructs. MSCs may participate directly in bone regeneration by differentiating into osteoblasts and producing bone tissue or indirectly by secreting trophic factors that promote 
osteogenic activity of endogenous cells in the defect site. ${ }^{46}$ Bone morphogenic proteins (BMPs), are members of the transforming growth factor (TGF- $\beta$ ) family and are well known for inducing bone formation. Bone morphogenetic protein-2 (BMP-2) is the most commonly used growth factor due to its superior osteoinductivity. ${ }^{47}$ It induces the differentiation of precursor cells with osteogenic potential, such as MSCs, into bone-forming osteoblasts. ${ }^{47}$ Osteoinductivity can also be a material property as scaffolds fabricated with certain macroand microstructural characteristics are osteoinductive. ${ }^{48,49}$ While the mechanism of material osteoinductivity is not well understood, it may be related to the co-precipitation of a biological apatite layer with osteoinductive proteins, which can occur in vivo. ${ }^{47,48,50,51}$ This is an important consideration when evaluating the bone regeneration capacity of chitosan-based scaffolds in vivo. Many of the studies on polymeric bone tissue engineering scaffolds as summarized in Table 1 utilized stem cells and/or growth factors in in vivo investigation to evaluate the bone regeneration potential of the scaffolds.

\section{Chitosan as a biomaterial for bone tissue engineering}

\subsection{Physicochemical properties of chitosan}

Chitosan is a derivative of chitin, a structural element found in the exoskeleton of crustaceans such as shrimp, crab and lobster. Commercially available chitosan results from alkaline deacetylation of chitin and as shown in Figure 2, chitosan is a linear polysaccharide composed of glucosamine and $\mathrm{N}$-acetyl glucosamine units linked by $\beta(1-4)$ glycosidic bonds. ${ }^{52}$ There are many forms of pure chitosan, which differ by their degrees of deacetylation (DD) and molecular weights. The degree of deacetylation represents the glucosamine to $\mathrm{N}$-acetyl-glucosamine ratio and generally falls in the range of 50-95\%. The molecular weight of commercially available chitosan ranges from $\sim 300$ to $1000 \mathrm{kDa}$ depending on the source and processing parameters. ${ }^{41}$ Both the degree of deacetylation and the molecular weight have a strong influence on other physicochemical properties of chitosan including crystallinity, solubility, and degradation. ${ }^{53}$ For instance, chitin $(0 \%$ deacetylation) and fully (100\%) deacetylated chitosan attain maximum crystallinity whereas chitosan with intermediate degrees of deacetylation is semi-crystalline. Chitosan is insoluble in neutral and basic solutions, but primary amines on deacetylated subunits of chitosan have a $\mathrm{pK}_{\mathrm{a}}$ of 6.5 , and thus chitosan forms water-soluble salts in both organic and inorganic acids. ${ }^{54}$ When solubilized, free amine groups become protonated and render chitosan positively charged. A higher degree of deacetylation corresponds to a higher percentage of positively charged primary amines and an overall higher charge density. This cationic nature is important for bone tissue engineering applications as chitosan can form polyelectrolyte complexes with anionic biological macromolecules. Specifically, anionic glycosaminoglycans such as heparin and heparan sulfate modulate the activity of several cytokines and growth factors important to bone regeneration. So chitosan modification with GAGs or chitosan association with GAGs in vivo could play a critical role in utilizing growth factors to aid in bone formation.

An important property of chitosan in the context of tissue engineering is the ease with which it can be functionalized. Reactive primary amines and primary and secondary hydroxyl groups present on chitosan allow for the addition of side groups, peptides or amino acids, all 
of which can be important for optimizing chitosan for bone tissue engineering applications. ${ }^{55}$ In addition, chitosan is amenable to graft polymerization. Chitosan degradation in vivo occurs via the action of lysozyme, which hydrolyzes glucosamineglucosamine, glucosamine-N-acetyl-glucosamine and $\mathrm{N}$-acetyl-glucosamine- $\mathrm{N}$-acetylglucosamine bonds resulting in chitosan oligosaccharides that are then incorporated into GAG or glycoprotein pathways, metabolic pathways or excreted ${ }^{56,57}$ Material degradation is inversely related to the degree of deacetylation (DD) so higher DD correlates with higher polymer crystallinity and thus with lower degradation rates. In addition, studies have shown that a higher chitosan molecular weight correlates with a lower degradation rate. ${ }^{58}$ Chitosan films made of high DD chitosan can remain intact for several months in vivo. ${ }^{56}$ For purposes of bone tissue engineering where the degradation rate must be tuned to accommodate bone ingrowth, the DD of chitosan may be selectively chosen to fabricate scaffolds that are appropriate for the target application.

\subsection{Biological properties of chitosan}

Chitosan possesses many biological properties that make it an important biomaterial. When implanted in vivo, chitosan evokes minimal foreign body response and fibrous encapsulation. ${ }^{59}$ Chitosan has been shown to accelerate wound healing by activating and modulating the function of inflammatory cells such as neutrophils, macrophages, fibroblasts and endothelial cells and by promoting the formation and organization of granulation tissue. ${ }^{56,60}$ Many of the interesting biological properties of chitosan can be attributed to its cationic nature. For example, it binds negatively charged red blood cells thereby promoting clotting and this hemostatic property has made it an important component in wound dressings. ${ }^{57}$ Similar to other cationic polymers, chitosan possesses antimicrobial properties. Although the mechanisms behind its antimicrobial nature are not completely understood, it is thought that because chitosan is cationic, it likely disrupts anions in bacterial cell walls leading to suppression of biosynthesis and disruption of mass transport across the cell walls. ${ }^{61}$ Chitosan functionality in terms of possessing amine and hydroxyl groups can be utilized directly to physically entrap or chemically conjugate growth factors. In addition, chitosan has been used as a drug excipient and its mucoadhesive properties are being studied for drug delivery because adherence of the polymer to a mucosal surface might result in enhanced or prolonged drug adsorption. ${ }^{55}$

Early work investigating chitosan as a potential biomaterial showed that certain modified chitosan, such as imidazole-modified chitosan and methylpyrrolidinone chitosan, are osteoconductive in vivo thereby promoting bone regeneration in surgically-created bone defects. $^{23,} 62$ Importantly, chitosan is hydrophilic meaning that it should support adhesion and proliferation of cells. In vitro studies have demonstrated that chitosan promotes the adhesion and proliferation of osteogenic cells and mesenchymal stem cells. ${ }^{22}$ Osteogenic cells cultured on chitosan deposit extracellular matrix which becomes mineralized to yield bone tissue. In addition, chitosan has also been implicated in promoting osteogenic differentiation of mesenchymal stem cells. ${ }^{63-65}$ 


\section{Scaffold fabrication methods}

\subsection{Bulk chitosan scaffolds}

The most frequently utilized method for fabrication of bulk chitosan scaffolds is the phase separation and lyophilization technique as depicted schematically in Figure 3a. 22, 41, 66-69 To utilize this technique, a chitosan solution is prepared in dilute acetic acid, introduced into a mold of interest and subjected to controlled freezing. Upon freezing, ice crystals form in the chitosan solution, and are phase-separated from the chitosan acetate salt. During the subsequent freeze-drying step, the ice crystals sublimate to yield a porous structure of solid chitosan material. Finally, the scaffold is neutralized and hydrated using sodium hydroxide and/or ethanol. The scaffold pore structure, in terms of pore diameter, orientation and interconnectivity, varies depending on multiple processing parameters including freezing temperature, thermal gradients, and polymer concentration. For example, the mean pore diameter of chitosan scaffolds can be controlled by adjusting the freezing temperature and thus cooling rate of chitosan solutions with lower freezing temperatures leading to faster cooling rates and resulting in smaller pores (Fig. 4a). ${ }^{41}$ Unidirectional thermal gradients can reduce pore interconnectivity due to parallel ice crystal growth whereas radial thermal gradients are more likely to result in ice crystal branching leading to enhanced interconnectivity. But radial thermal gradients, commonly associated with surface cooling of a chitosan solution in a glass mold, can lead to differences in ice nucleation conditions at the solution-mold interface and the formation of two levels of porosity within a scaffold (Fig. bb). ${ }^{41}$ Care must be taken to maximize uniformity of the porous structure by maintaining uniform cooling throughout the chitosan solution. Higher chitosan concentrations correlate with smaller pores and increased pore wall thickness due to higher chitosan mass per unit volume. This, in turn, correlates with enhanced scaffold mechanical strength. ${ }^{59}$ One major drawback of the phase separation technique is the formation of a surface skin if the porous scaffold matrix collapses at the scaffold-air interface due to interfacial tension during solvent evaporation. ${ }^{70}$ This surface skin, with a non-porous structure, can block nutrient exchange and oxygen diffusion into the scaffold, which would be highly detrimental to tissue formation and ingrowth. Additionally, uniform scaffold porosity can be difficult to achieve because freezing conditions can vary throughout a given scaffold volume. Overall, although phase separation and lyophilization has its limitations, it is a relatively simple method for fabrication of bulk chitosan scaffolds.

In the context of bulk chitosan scaffolds, the particulate leaching method is often combined with phase separation and lyophilization to fabricate chitosan scaffolds, where a sacrificial porogen is mixed with the chitosan solution and then leached out into a solvent following the lyophilization step (Fig. 3b). This results in two levels of porosity generated by the multi-step process. ${ }^{71,72}$ Commonly-used porogens in creating porous structures include salts, sugars, paraffin and gelatin. Pore size and extent of porosity can be controlled by the type, size and concentration of porogens. For example, sodium chloride, a cubic-shaped porogen, generates higher scaffold porosity, thinner pore walls and enhanced pore interconnectivity at higher porogen concentrations. Given a constant porogen concentration, a larger diameter salt particle leads to larger diameter pores, thinner pore walls and thus lower scaffold mechanical strength. ${ }^{73}$ Some studies reported that spherical porogens, such as 
gelatin and paraffin microspheres, result in more uniform pore morphology and pore interconnectivity than cubic salt particles. ${ }^{74,75}$ Common porogens are generally inexpensive and easy to handle, but one drawback of particulate leaching is that it can be time consuming and therefore inefficient. In addition, there can be a lack of control of pore interconnectivity during processing because porogens are dispersed within the polymer phase.

As an alternative to the use of a solid phase to induce porosity, gas foaming exploits the nucleation and growth of gas bubbles within a polymeric matrix to yield a porous structure. ${ }^{70}$ Gas bubbles form by either (1) mixing a foaming or blowing agent, such as sodium bicarbonate, with a pre-polymer where gas is generated upon chemical decomposition $^{76,77}$ or (2) saturating a polymer with subcritical or supercritical gas at high pressure where depressurization results in thermodynamic instability leading to nucleation, growth and coalescence of gas bubbles as illustrated in Figure 3c. ${ }^{78,79}$ Gas foaming does not necessitate the use of organic solvents, but pore formation and porosity depend on rate of nucleation and gas diffusion, which can be difficult to control ${ }^{80}$ Carbon dioxide is often used for foaming of biomaterials because of its moderate critical temperature $\left(31^{\circ} \mathrm{C}\right)$ and pressure ( $73 \mathrm{bar}$ ) and low toxicity. ${ }^{78}$ Gas foaming with supercritical carbon dioxide has been used for fabrication of porous chitosan scaffolds. ${ }^{56}$ Some PLA and PLGA systems have been optimized in terms of parameters associated with supercritical $\mathrm{CO}_{2}$ foaming and these reports may provide some insight into optimization of chitosan systems. Studies of gasfoamed PLA and PLGA scaffolds show that at constant pressure, a higher processing temperature (above the critical temperature of $\mathrm{CO}_{2}$ ) during foaming leads to a larger diameter and more open pores in the resultant porous structure. Given a constant temperature, higher soaking pressure allows for the diffusion and incorporation of more $\mathrm{CO}_{2}$ into the polymer. In this case, when the system is depressurized, there is a higher nucleation density resulting in pores of smaller diameters. When the temperature and pressure are held constant, slower depressurization of $\mathrm{CO}_{2}$ slows the gas nucleation, which facilitates the growth and coalescence of gas bubbles leading to pores of larger diameters. ${ }^{81,} 82 \mathrm{As}$ previously mentioned, mechanical properties of porous scaffolds are intimately dependent on pore diameter and overall porosity where larger and more interconnected pores correlate with lower mechanical strength due to higher void volume.

Freeze gelation is another method applied to chitosan scaffold fabrication and is based on the principle of phase separation. Instead of lyophilization, phase separated chitosan is exposed to a sodium hydroxide/ethanol solution at $-20^{\circ} \mathrm{C}$ to induce gelation (Fig. 3d). In this case, the gelation of chitosan occurs below the freezing temperature of chitosan and prior to the drying stage thus preserving the porous structure of the scaffold without the need for freeze-drying. ${ }^{83}$ The sodium hydroxide/ethanol solution is removed from the scaffold by air-drying at room temperature following gelation. Similar to the technique of phase separation with lyophilization, the mean pore diameter can be adjusted by changing the freezing temperature and thus the cooling rate of the polymer solution where lower freezing temperatures correlate with faster cooling and smaller pore diameter. Pore interconnectivity is related to the direction of temperature gradients during cooling. Unidirectional gradients promote parallel ice crystal growth thereby minimizing pore interconnectivity whereas radial gradients promote the intersection of ice crystals and thus enhance pore interconnectivity. Chitosan solution concentration affects pore diameter, pore wall thickness 
and thus scaffold mechanical properties whereby higher concentrations correlate with smaller pores and thicker pore walls. ${ }^{84}$ Whereas lyophilization can be time and energy intensive, freeze gelation can be a more efficient process that also minimizes the presence of residual acetic acid in scaffolds. ${ }^{85}$ Care must be taken, however, to optimize the freeze gelation system to minimize local melting during gelation. This can occur due to the exothermic reaction that results when frozen acetic acid solvent and sodium hydroxide gelation solution are mixed. ${ }^{85}$

\subsection{Chitosan scaffolds made by rapid prototyping}

Rapid prototyping technology encompasses a category of fabrication methods that utilize computer-aided design (CAD) and computer-aided manufacturing (CAM) to produce scaffolds with strictly defined architecture (Fig. 5a). ${ }^{86}$ There are many rapid prototyping techniques available where the commonality among them is the printing or deposition of a periodic structure in an additive, layer-by-layer fashion where the periodic scaffold structure is formed by intersecting struts as illustrated in Figure 5b. When using rapid prototyping technology to fabricate scaffolds, the most common method is an indirect one where molds of wax ${ }^{87}$ or PDMS ${ }^{88}$ with the inverse scaffold structure are deposited and then used to cast chitosan solutions into scaffolds (Fig. $5 \mathrm{c}, \mathrm{d}$ ). This indirect rapid prototyping technique is often combined with freeze gelation or phase separation to generate scaffolds with both a periodic macrostructure defined by scaffold strut diameter and strut spacing and microstructure due to phase separation within the struts (Fig. 5e). ${ }^{89}$ A significant advantage of the rapid prototyping technology is the strict control over scaffold pore size, shape and interconnectivity. As scaffold porosity dictates the mechanical strength, optimization of these properties is critical and this technology allows for precise changes to scaffold architecture allowing for systematic variations to optimize porosity and thus mechanical strength. In addition, the rapid prototyping technology can be combined with medical imaging technology to fabricate customized implants with complex geometries. ${ }^{90}$ One drawback of rapid prototyping technology for fabricating scaffolds from natural polymers is the use of the indirect or inverse method, which requires casting of scaffolds using rapid prototyped molds. This increases the complexity of the fabrication process compared to direct writing. Overall, RP technology is not highly accessible and therefore is not as versatile as more traditional methods described above. Technology for direct printing of chitosan remains under development, but may be very useful for fabrication of chitosan scaffolds.

\subsection{Microparticle-based chitosan scaffolds}

Chitosan scaffolds can be fabricated through the fusion or sintering of chitosan microparticles or microspheres. ${ }^{91,92}$ Multiple techniques have been developed for formation of chitosan microparticles and microspheres with the most common methods including ionotropic gelation and chemical crosslinking with agents such as glutaraldehyde or genipin. ${ }^{93}$ Scaffolds can be formed by mixing, compressing and drying hydrated microspheres that have been packed into a mold. ${ }^{94}$ Alternatively, dry microspheres can be mixed with a small volume of acetic acid to promote surface dissolution and expedite particle aggregation once the particles are placed into a mold for heating and drying. ${ }^{92}$ Sintered/fused microparticle scaffolds tend to possess more optimal mechanical properties 
for applications in bone tissue engineering because the pore walls are composed of the microparticles themselves and therefore the scaffolds have a higher density than scaffolds formed via phase separation. One drawback of sintered microparticle scaffolds is the low level of overall porosity, which is generally less than $40 \%$ compared to $>90 \%$ exhibited by scaffolds prepared via the phase separation technique. Such low porosity may be insufficient to support cell infiltration, neovascularization and tissue ingrowth. ${ }^{92,95}$ Increasing sintering temperature or sintering time for processing of chitosan-PLGA microsphere scaffolds resulted in an increase in compressive modulus and compressive strength as well as an increase in median pore size, but was accompanied by a decrease in overall porosity. ${ }^{92}$ The decrease in overall porosity may be due to greater fusion of microspheres leading to pore closure. This is an example of the difficult balance in the design of bone tissue engineering scaffolds where there is a trade-off between scaffold porosity and mechanical strength.

\subsection{Nanofiber-based chitosan scaffolds}

Polymeric nanofibers have garnered significant attention as a material platform for tissue engineering because their structure is similar to proteoglycans and fibrous proteins found in natural extracellular matrix. ${ }^{18}$ For example, mineralized collagen fibrils found in bone have a diameter of approximately 50-100 nm. ${ }^{25,} 96$ The high surface area-to-volume ratio of nanofibers and the high porosity of nanofiber mats and scaffolds render them promising for a wide range of biomedical applications. Various methods have been utilized to generate polymer nanofibers including phase separation, ${ }^{97}$ template-assisted synthesis, ${ }^{98}$ selfassembly, ${ }^{99}$ drawing, ${ }^{100}$ wet spinning, ${ }^{101,102}$ and electrospinning. ${ }^{103,104}$ Electrospinning is a favorable route for fabrication of polymeric nanofibers because the apparatus (Fig. 6a) is relatively simple and the process relatively inexpensive. To make nanofibers by electrospinning, a polymer solution is held in a liquid dispenser such as a syringe and an electric field is applied between the solution and the collection plate. A droplet of the polymer solution becomes charged and is deformed into a conical shape after leaving the syringe tip and then further stretched to allow for drawing of a fiber from the liquid. This occurs because electrostatic repulsion of surface charge on the polymer solution surmounts the surface tension. ${ }^{105} \mathrm{~A}$ charged liquid stream is achieved where the high surface charge density causes bending of the stream to yield a fiber that solidifies due to solvent evaporation. Randomly-oriented nanofibers can be collected directly on a stationary collector plate whereas aligned fibers are often collected using a rotating mandrel where the degree of the alignment depends on the speed of mandrel rotation. ${ }^{18,106}$ Studies have shown that faster rotating speeds correlate with a higher degree of fiber alignment. ${ }^{106}$

Natural polymers, like chitosan, are generally less spinnable than their synthetic counterparts because of their limited solubility in most organic solvents, high molecular weight, polycationic character in the dissolved state, and 3-D networks of strong hydrogen bonds. ${ }^{103}$ Specifically, chitosan is difficult to electrospin because of the low solubility of chitosan and the high viscosity of chitosan solutions. Yet researchers have found some success in electrospinning pure chitosan (Fig. 6b) and composite chitosan nanofibers. ${ }^{18,103,104,107}$ Chitosan nanofiber systems require significant optimization of polymer solution properties such as polymer concentration and solvent concentration. Other important parameters to consider include electric field strength, solution feed rate and the distance between the 
syringe tip and collection plate. ${ }^{108}$ In general, when the polymer concentration/viscosity is too low, there is insufficient material to form stable, solid fibers and instead, droplets or beads are formed. ${ }^{18}$ Yet if concentration and viscosity are too high, it is impossible to achieve continuous flow. At an optimal concentration, fibers can be drawn and increased concentrations generally correlate with larger fiber diameters. ${ }^{109}$ Polymer flow/feed rate defines the amount of solution available and plays a role in fiber diameter. A low flow rate generally results in small fiber diameters. Flow rates that are too high can lead to fibers that are still wet upon collection because there is insufficient time for solvent volatilization. ${ }^{109}$ Correspondingly, a minimum distance must be established between the syringe tip and collector to allow for collection of dry fibers. In terms of electric field strength, higher voltages correlate with smaller fiber diameters and yet can lead to the formation of bead defects. ${ }^{107}$ Overall, the main commonality among studies reporting electrospinning of chitosan is that there are narrow parameter windows for any given system in terms of spinnability, and the optimization of operation parameters is required.

\subsection{Chitosan-based hydrogel scaffolds}

An important category of chitosan-based materials useful for application in bone tissue engineering is that of chitosan-based hydrogels. Hydrogels are crosslinked polymer networks with a high density of hydrophilic groups within the polymer chains. This hydrophilicity promotes polymer hydration and thus renders the polymer with high water content. Hydrogel dissolution is prevented due to crosslinking, which can be achieved via non-covalent interactions such as physical entanglements or ionic bonding or by covalent means involving small molecule crosslinkers or secondary polymerization of prefunctionalized polymer chains. Detailed discussion of chitosan hydrogel formation and mechanisms associated with chitosan-based hydrogel crosslinking is covered by Bhattarai et al. ${ }^{110}$ Hydrogels are generally utilized in bone tissue engineering as a controlled delivery system for localized, sustained delivery of cells and/or growth factors. In order to effectively serve as bone tissue engineering scaffolds, hydrogels must 1) possess sufficient structural integrity and mechanical strength to occupy the given bone defect, 2) maintain the viability and/or bioactivity of biological agents being applied to the defect site to promote cell migration, proliferation and/or differentiation in support of tissue regeneration and 3 ) degrade in concert with tissue regeneration.

Examples of chitosan-based hydrogels for bone tissue engineering include pure chitosan, ${ }^{111}$ chitosan/glycerol phosphate, ${ }^{112}$ chitosan- $g$-poly(N-isopropylacrylamide), ${ }^{113}$ chitosan/ lactide, ${ }^{114}$ and chitosan/poly(ethylene oxide). ${ }^{115}$ In addition, chitosan-based nano- or microparticles are often combined with polymeric hydrogels to promote bone regeneration. ${ }^{116-118}$ Hydrogels are advantageous as scaffolds because they provide a good environment for encapsulation and localized delivery of cells and/or bioactive molecules. Care must be taken in designing hydrogel systems for this purpose as some methods of crosslinking can harm or denature cells or growth factors. Injectable hydrogels that undergo gelation in situ are especially useful for tissue engineering because they can be applied in vivo in a non-invasive manner or easily combined with other scaffold materials. Depending on the specific system, in situ gelation can be achieved by photocrosslinking with UV light ${ }^{114}$ or temperature-induced crosslinking. ${ }^{112,113,115,119,120}$ Hydrogels are generally 
elastic and rubbery, similar to natural tissues, and hydrogels easily adopt the geometry of the space that they occupy, meaning that they can be applied to irregularly shaped defects. One disadvantage of hydrogels is their poor mechanical properties, which can be overcome when hydrogels are combined with other scaffold materials.

\section{Preparation of composite polymer-based chitosan scaffolds}

While chitosan possesses many properties that make it a favorable material for bone tissue engineering, some of its properties are sub-optimal. For example, it is mechanically weak and the compressive modulus of the vast majority of pure chitosan scaffolds remains one or two orders lower in magnitude than that of cancellous bone (Table 2). Chitosan also lacks structural stability in aqueous environments. It cannot maintain a predefined shape when hydrated, which is a critical requirement of implantation in a defect site as it should act as filler within the site in addition to facilitating bone regeneration processes. Therefore chitosan is often blended with other synthetic or natural polymers in order to improve its mechanical properties and structural integrity when hydrated.

\subsection{Physical blends}

A simple method for forming polymeric composite scaffolds is to physically mix two or more polymers prior to scaffold fabrication. Formation of a single homogenous phase comprising chitosan and a synthetic polymer, such as a polyester, is difficult to achieve because of lack of co-solvents that can accommodate both polymers. Thus in one study, mechanical stirring was utilized to form a homogenous suspension of milled chitosan microparticles in a solution of PLGA in methylene chloride. Subsequently, composite chitosan-PLGA microspheres were formed via solvent evaporation and microspheres fused to yield scaffolds. ${ }^{92}$ Chitosan has also been combined with polyesters using a method called melt blending where heating and compression of polymer particles results in the formation of a continuous polymer network. ${ }^{121-124}$ Combined with leaching of salt particles, melt blending yields porous scaffolds and in both cases, mechanical strength of the resultant scaffolds exceeded that of pure chitosan scaffolds.

\subsection{Polyelectrolyte complexes}

Polyelectrolyte complex networks form between chitosan and anionic macromolecules due to electrostatic interactions among charged functional groups. ${ }^{110}$ Chitosan-based polyelectrolyte complexes (PECs) useful for bone tissue engineering include chitosan complexed with alginate, gelatin and chondroitin sulfate. ${ }^{69,125-129}$ In particular, chitosanalginate (CA) scaffolds result from the complex formed between chitosan amino groups and alginate carbonyl groups. These scaffolds are fabricated by mixing individual polymer solutions and then utilizing any of the fabrications methods described above to create the final polymer complex scaffold. PEC scaffolds are generally stronger than scaffolds fabricated from the individual materials that constitute the PEC. Interestingly, the mechanical strength improves despite an increase in the overall porosity of PEC scaffolds, which is a result of a more open network structure. ${ }^{69,125,130}$ In addition, the structural stability of chitosan-based PEC scaffolds in aqueous environments is superior to pure chitosan scaffolds. ${ }^{125}$ 


\section{Chitosan-calcium phosphate composite scaffolds}

Pure chitosan is a suitable substrate for attachment and proliferation of osteogenic cells such as mesenchymal stem cells, but it does not induce bone formation nor does it form a bond with bone. Calcium phosphates (CaPs), on the other hand, are bioactive, meaning that they bond to bone, and are osteoconductive and in some cases, osteoinductive. They are similar in chemical composition to the mineral phase of bone and the most biologically relevant forms include hydroxyapatite (HA), tricalcium phosphate (TCP), biphasic calcium phosphate (BCP), octacalcium phosphate (OCP) and dicalcium phosphate dehydrate all of which differ in terms of $\mathrm{Ca} / \mathrm{P}$ ratio, crystal structure and rate of dissolution. ${ }^{131}$ While monolithic, macroporous calcium phosphate scaffolds are generally too brittle for use on their own, chitosan-calcium phosphate composite scaffolds often fulfill the requirements of scaffolds for non-load-bearing bone graft applications. Most importantly, calcium phosphates have been shown to enhance osteoblast response and direct mesenchymal stem cell phenotype thus improving the biological response to chitosan scaffolds. ${ }^{33,51,132}$

\subsection{Calcium phosphate coatings on chitosan scaffolds}

Calcium phosphate can be combined with chitosan scaffolds via the direct formation of a synthetic coating or biological apatite layer on the chitosan scaffold surface. Calcium phosphate coatings enhance the bone bonding ability of chitosan scaffolds as well as their osteoconductivity. ${ }^{33}$ The coatings can be created on chitosan scaffolds (1) by soaking scaffolds in simulated body fluid (SBF), (2) by soaking scaffolds in a heated solution containing $\mathrm{Ca}^{2+}$ and $\mathrm{PO}_{4}{ }^{3-}$ in ethanol solution ${ }^{89}$ or (3) via a double diffusion method. ${ }^{87}$ Soaking scaffolds in SBF mimics some aspects of natural biomineralization in vivo as the solution ionic components, $\mathrm{pH}$ and temperature are similar to that of blood plasma. ${ }^{133}$ Here the biomineral is nucleated onto surfaces from aqueous solution so this process is fairly versatile and can accommodate scaffolds of varying materials and geometries. Apatite formation via SBF is accelerated on chitosan-chondroitin sulfate and chitosan-alginate scaffolds compared to that on pure chitosan scaffolds, and MSCs proliferated more rapidly on apatite coated scaffolds. ${ }^{69}$ It is possible that the negative charges associated with chondroitin sulfate and alginate promote electrostatically-driven accumulation of $\mathrm{Ca}^{2+}$ on the scaffold surface thereby inducing nucleation and growth of the apatite layer. ${ }^{134}$ The double diffusion method involves diffusion of previously segregated calcium and phosphate ions into the scaffold allowing for precipitation of an apatite layer on scaffold pore walls in manner.

\subsection{Calcium phosphate particles in bulk chitosan scaffolds and nanofiber mats}

Another route to fabrication of composite chitosan-calcium phosphate scaffolds is to physically mix calcium phosphate particles with chitosan prior to scaffold fabrication. This has been reported using calcium phosphate microparticles ${ }^{135136}$ and more recently attention has shifted to the incorporation of nano-hydroxyapatite (nanoHA) within chitosan materials. The nanoHA particles, as compared to micro-scale HA particles, more closely resemble the biological apatite found in bone in terms of size-scale, and the increased surface area to volume ratio of the nanoscale material enhances the interaction of the particles with polymeric matrices. HA nanoparticles can be incorporated into chitosan scaffolds in a 
number of ways. They can be physically blended with chitosan solutions or co-precipitated with chitosan. As HA is insoluble in neutral and basic solutions and precipitation of chitosan occurs in solutions with $\mathrm{pH}>6$, the conditions for precipitation of both materials are almost the same. In situ co-precipitation forms the mineral phase in association with the polymer phase during physiological mineralization of bone resulting in strong interfacial bonding of the mineral and the polymer. Physical mixing is a simple and quick process, but in situ coprecipitation may be advantageous because a more homogeneous distribution of HA in the polymer matrix can be achieved and the resultant nanoparticles are more intimately integrated into the polymer matrix. ${ }^{137}$ Co-precipitated chitosan and nanoHA show good miscibility at various nanoHA/chitosan weight ratios ${ }^{138}$ and a degree of control can be exerted on the size of nanoHA particles by varying the weight proportion of chitosan to calcium and phosphate ions in solution. ${ }^{139}$ Similar to bulk chitosan scaffolds, nanoHA particles can be introduced into chitosan nanofibers through physical mixing or coprecipitation within the chitosan solution prior to electrospinning. ${ }^{140-142}$

\section{Evaluation of physicochemical and biological properties of chitosan scaffolds in vitro}

Similar to other types of scaffolds, the in vitro evaluation of chitosan-based bone tissue engineering scaffolds generally begins with characterization of scaffold microstructure in terms of pore size, shape and interconnectivity. Scanning electron microscopy is the primary method for visualizing scaffold pores, and the technique known as "liquid displacement" is commonly used to determine overall scaffold porosity. ${ }^{143,144}$ Pore size and distribution are characterized by mercury intrusion porosimetry where chitosan scaffolds are initially placed in a chamber and subjected to high vacuum. The pressure is then applied to mercury, a nonwetting liquid, to force it into scaffold pores. ${ }^{145}$ The pressure required to fill the scaffold pores with mercury is correlated with the pore size, and increased pressure is required for smaller pores. Care must be taken when applying this method to chitosan scaffolds because a vacuum that is too high could result in collapse of the scaffold and its pores. X-ray diffraction analysis provides information about scaffold crystallinity, and Fourier transform infrared spectroscopy (FTIR) is commonly used to examine phase changes or chemical composition of composite scaffolds. Chitosan scaffolds swell easily in aqueous solution due to the high density of protonated amine groups that have a strong affinity for water molecules. It is necessary to neutralize or crosslink chitosan scaffolds in order to reduce swelling. Neutralization can be achieved by soaking the scaffolds in a basic solution such as sodium hydroxide or ammonium hydroxide. Commonly used crosslinking agents for chitosan scaffolds include covalent crosslinkers such as glutaraldehyde and genipin and physical crosslinkers such as calcium chloride and tripolyphosphate that form ionic complexes. ${ }^{110}$ Crosslinking agents such as glutaraldehyde are generally not favorable as they are often toxic even in trace amounts and therefore harmful to cells and tissues. ${ }^{146}$ Water uptake and retention by chitosan scaffolds are measured by weighing dry versus hydrated scaffolds, and scaffold swelling is determined by measuring changes in hydrated scaffold diameter over time. 
Mechanical strength of chitosan-based scaffolds is a critical property generally characterized via compression testing. Many studies on chitosan-based scaffolds report the compressive modulus and/or strength because bone is principally loaded in compression in vivo. Yet it is difficult to directly compare the mechanical properties of chitosan scaffolds among different studies because raw material properties such as molecular weight and degree of deacetylation can differ significantly between studies. In addition, factors related to the process of mechanical testing can differ, such as strain rate applied during compression and scaffold hydration state. We present the mechanical properties of some chitosan and composite chitosan scaffolds in Table 2 to illustrate the differences in mechanical properties among pure chitosan scaffolds reported in different studies as well as the differences between pure chitosan and composite chitosan scaffolds reported in individual studies. This summary of studies also shows that there is a significant difference in compressive moduli between dry and hydrated scaffolds where hydrated scaffolds posses significantly reduced moduli compared to dry scaffolds. Compressive properties in the hydrated state are likely to be more relevant because scaffolds are hydrated within the in vivo environment, but strength and/or moduli values are often reported for dry scaffolds. Overall, the compressive moduli of pure chitosan scaffolds fabricated using methods such as phase separation and gas foaming fall far below that of cancellous bone $(100-500 \mathrm{MPa})^{37,38}$ although there is an increase in modulus observed with increased chitosan concentration. The compressive and tensile strengths and moduli reported for cancellous/trabecular bone (Table 2) represent a range of values due to variation among anatomical location and bone density. ${ }^{147}$ While the tensile strength is generally lower than the compressive strength, the compressive and tensile Young's modulus are not significantly different. ${ }^{40}$ Fabrication methods such as particle aggregation and rapid prototyping can generate scaffolds with an overall porosity below $50 \%$ and these scaffolds display higher compressive moduli due to the higher pore wall thickness in the porous structure and lower fraction of overall pore space. Specifically, in Table 2, only scaffolds fabricated via particle aggregation exceeded the lower limit of cancellous bone compressive modulus (>100 MPa). Whereas scaffold fabricated via particle aggregation do not achieve overall porosity higher than 50\%, in the case of rapid prototyping, scaffold porosity can be controlled based on strut diameter and spacing so the overall porosity can be greater than $50 \%$. While the mechanical properties of particleaggregated chitosan-based scaffolds are superior compared to those derived from other methods, the low overall porosity is suboptimal for promoting tissue regeneration.

In vitro cell culture studies are used to examine cell-scaffold interactions in terms of cell attachment, viability, proliferation and osteoblastic differentiation. Prior to initiating in vitro cell culture studies, chitosan scaffolds must be sterilized. Because the scaffolds can be damaged when autoclaved at high temperature and pressure, they are sterilized using ethanol solution or ethylene oxide gas. Cells and cell lines commonly used for in vitro testing of chitosan scaffolds include: MG-63 human osteosarcoma cells, MC3T3-E1 pre-osteoblast cells derived from mouse calvaria, CH310T1/2 mouse embryonic stem cells and mesenchymal stem cells (MSCs) from various species. Cell activities that are monitored to evaluate compatibility of osteoblasts with chitosan scaffolds include cell proliferation, extracellular matrix deposition and maturation and finally, matrix mineralization. Osteoblastic differentiation of pre-osteoblasts and stem cells is often measured based on 
temporally-defined expression of markers such as alkaline phosphatase, osteocalcin and osteopontin. ${ }^{148}$ Alkaline phosphatase enzyme activity and mRNA expression increase following osteogenic cell proliferation, reach a maximum during the matrix maturation stage, and decrease at the onset of mineralization. ${ }^{149}$ As matrix mineralization is initiated, expression of genes for bone-related non-collagenous proteins such as osteocalcin, bone sialoprotein and osteopontin is initiated and increases. The exact role of these proteins in bone matrix is not clearly defined, but they are all believed to play a role in regulation of mineralization. 43

\section{In vivo evaluation of chitosan scaffolds}

The first step in the in vivo evaluation of newly developed chitosan-based scaffolds involves implantation of the scaffold in a subcutaneous or intramuscular site of a small animal model, such as mice or rats, to determine tissue compatibility and extent of cell infiltration and neovascularization. $66,125,150$ Sometimes scaffolds are implanted intramuscularly to evaluate scaffold osteoinductivity in terms of potential ectopic bone formation. ${ }^{151} \mathrm{Next}$, the chitosan scaffold is implanted in an orthotopic site to evaluate its bone-regenerating capacity. The most useful type of surgically-created bone defect for this purpose is a critical size defect. Critical size defects are too large to heal spontaneously so any bone regeneration observed is attributed to the scaffold and/or biologics that are introduced to the defect site. Examples of animal models and corresponding defect sites used to evaluate chitosan-based scaffolds are summarized in Table 3. Many researchers utilize mouse or rat calvarial defects as first line, small animal models of non-load-bearing, critical-sized bone defects. ${ }^{46,} 152$ Chitosan-based scaffolds or other tissue engineering constructs are placed in defects and then retrieved at predetermined time points.

Common methods of evaluating the bone regeneration capability of chitosan scaffolds implanted in surgically-created defects include radiography, microcomputed tomography (micro-CT) and histological staining. Radiography utilizes x-rays to provide twodimensional projection images of bone at a relatively low resolution allowing researchers to have a first-line, macro view of possible bone regeneration in a defect site. Radiography is preferable as an initial examination modality because it can be utilized to track bone regeneration over a time course without having to sacrifice animals for sample retrieval. Xray attenuation by mineralized bone is significantly higher than attenuation by chitosan material, so macro-quantities of mineralized bone within a defect site can be easily detected. Micro-CT is a radiographic imaging modality at a higher resolution. Two-dimensional radiographs captured via micro-CT can be reconstructed allowing data to be manipulated as a $3 \mathrm{D}$ object as opposed to a series of 2D projections. Knowing the size of the surgicallycreated defect and the chitosan scaffold used to fill the defect, it is possible to quantify newly mineralized bone and determine the extent of defect closure. In some cases, micro-CT can be applied to live, but sedated small animals for imaging during the time course of the study. Histology is a very powerful tool for visualizing bone regeneration at the cellular level. The process requires retrieval, fixation, embedding, sectioning and staining of explants. Chitosan scaffolds with bone that has been demineralized are embedded in paraffin whereas chitosan scaffolds containing mineralized bone can be embedded in poly(methyl methacrylate) (PMMA). Hematoxylin and eosin is a basic histological stain combination 
that allows for visualization of cellular details and is commonly applied to paraffinembedded sections. Demineralized bone is generally stained pink with osteocytes, stained blue, distributed throughout the bone matrix. More specialized stains and stain combinations have been developed for bone histology including toluidine blue, ${ }^{153,}{ }^{154}$ Von Kossa, ${ }^{155}$ Goldner's trichrome, ${ }^{156}$ and Sanderson's rapid bone stain/acid fuchsin, ${ }^{157}$ to name a few. Some of these stains are applied to PMMA-embedded samples and can distinguish between osteoid and mineralized bone, which is not possible with standard hematoxylin and eosin staining.

\section{Advances in chitosan-based scaffolds for bone tissue engineering}

Many advances have been made in developing chitosan-based scaffold technology for bone tissue engineering in the past few years.

\subsection{Chitosan scaffolds}

Pure chitosan scaffolds are generally not well-regarded for purposes of bone tissue engineering because of their weak mechanical strength. A recent study reported fabrication of pure chitosan scaffolds via phase separation where the chitosan concentration is in the range of 4-12 wt $\%{ }^{59}$ At the highest chitosan concentration (12 wt $\%$ ), pure chitosan scaffolds had an average compressive modulus of $17.99 \pm 0.11 \mathrm{MPa}$. It is generally difficult to prepare chitosan solutions in acetic acid with a chitosan concentration above $4 \mathrm{wt} \%$ due to high solution viscosity. In this study, optimization of solvent acidity and polymer concentration allowed for preparation of chitosan solutions greater than $4 \mathrm{wt} \%$ that could be utilized for scaffold preparation. All scaffolds in this study had a pore size in the range of 100-500 $\mu \mathrm{m}$, but overall porosity decreased and pore wall thickness increased with an increase in chitosan concentration. Higher mechanical strength, lower swelling and better structural integrity in aqueous environments are observed and can be attributed to the increased pore wall thickness. In addition, the chitosan material exhibited increased crystallinity at higher chitosan concentrations, which also played an important role in improving scaffold mechanical properties. MG-63 cell proliferation was significantly greater on $12 \mathrm{wt} \%$ chitosan scaffolds than on $4 \mathrm{wt} \%$ chitosan scaffolds over a course of 7 days in culture. This shows the importance of cell-substrate interactions where in this case, scaffolds with higher mechanical strength are more effective in promoting osteogenic cell proliferation. Thus pure chitosan scaffolds retain utility for bone tissue engineering, and in vivo studies are needed to further investigate the potential of these high strength scaffolds in bone tissue engineering.

\subsection{Polymer-based composite chitosan scaffolds}

Among polymer-based composite chitosan scaffolds, polyelectrolyte complex (PEC) scaffolds show significant improvements in multiple scaffold properties as compared to pure chitosan scaffolds, and like pure chitosan scaffolds, they are relatively easy to fabricate. Chitosan has been blended with alginate to fabricate a PEC scaffold via phase separation; the microstructures of chitosan and chitosan-alginate (CA) scaffolds are shown in Fig. 7a-d. The CA complex scaffold exhibits significantly-elevated compressive modulus and strength compared to pure chitosan scaffolds (Table 2). ${ }^{125}$ In addition, less swelling was observed 
with the CA scaffold upon hydration, which enhanced its overall structural stability. Water retention and thus swelling of hydrogel-based porous scaffolds in an aqueous environment is an important property because swelling increases porosity and surface area in support of cell attachment and tissue regeneration. But continuous or excessive swelling is detrimental to scaffold integrity. Swelling of pure chitosan scaffolds is pH-dependent (Fig. 7e) making it unsuitable for in vivo environments. CA scaffolds swell, but retain their swollen shape and structural integrity for an extended period of time. This improved stability may be attributed to a decrease in protonation of chitosan amino groups due to complexation with alginate and the buffering capacity of alginate carboxyl groups to maintain a more neutral $\mathrm{pH} .{ }^{125}$

As another example of chitosan-based PECs, carboxyl groups of the anionic protein, gelatin, can form a network with cationic chitosan through hydrogen bonding. Gelatin, generated through the hydrolysis of collagen, retains the RGD-like sequences of collagen, which promotes cell adhesion and enhances cell spreading via integrin binding. ${ }^{126} \mathrm{~A}$ study has shown that the complexation of chitosan and gelatin decreases scaffold crystallinity yielding a more amorphous structure that is less amenable to degradation. ${ }^{127}$ Therefore a degree of control can be exerted on scaffold degradation by controlling the ratio of gelatin to chitosan in solution and can be potentially applied to PEC systems composed of chitosan and other anionic polymers. The ability to tune the scaffold degradation rate is important for bone tissue engineering applications as degradation must not occur prior to the initiation of bone regeneration and at the same time, should not impede bone regeneration.

\subsection{Chitosan-based hydrogel scaffolds}

Thermally-induced gelation of chitosan occurs in various chitosan-based hydrogel systems including chitosan-glycerophopshate, ${ }^{112,120}$ chitosan-poly(ethylene glycol), ${ }^{115,119}$ and graft co-polymers of chitosan and poly(N-isopropylacrylamide). ${ }^{113}$ Recently, a chitosan-collagen hydrogel microbead was reported as a vehicle for culture and delivery of cultured-expanded mesenchymal stem cells or fresh bone marrow mononuclear cells. ${ }^{117}$ The microbeads were fabricated via a two-step process. Chitosan, collagen and $\beta$-glycerophosphate were mixed in solution and bead formation was achieved using a water-in-oil emulsion system followed by thermally induced gelation at physiological temperature. This process was carried out with cells of interest dispersed within the pre-polymer solution with maintenance of cell viability during fabrication. Both fresh bone marrow mononuclear cells and cultured expanded MSCs could be induced to undergo osteogenic differentiation in vitro making this a promising vehicle, when combined with bulk collagen-chitosan hydrogel for promoting bone regeneration within a defect site. Poly(N-isoproprylacrylamide) (PNIPAM), is a well known thermo-responsive hydrogel polymer with a lower critical solution temperature of $37^{\circ} \mathrm{C}$, above which the polymer undergoes a sol-gel transition. Yet a limitation in using PNIPAM for purposes of bone tissue engineering is its lack of biodegradability and biocompatibility. To improve upon these deficiencies, PNIPAM has been modified, via grafting, with natural polymers. A recent study describes a hyaluronic acid- $g$-chitosan- $g$-PNIPAM copolymer where the presence of hyaluronic acid and chitosan renders the copolymer more biocompatible and biodegradable. ${ }^{113}$ The hydrogel was used to encapsulate bone marrowderived mesenchymal stem cells for in vitro studies to characterize cell proliferation, osteogenic differentiation and osteogenic activity. In vitro culture within the hydrogel 
resulted in enhanced proliferation and osteogenic activity following differentiation compared to cells cultured on tissue culture polystyrene. In addition, the cell-hydrogel construct was stronger and more elastic after osteogenic differentiation of the BMSCs. Canine BMSC-loaded hydrogel solutions were injected subcutaneously in nude mice and results showed ectopic bone formation, which did not occur for hydrogels without cells.

An example of a photocrosslinkable chitosan-based hydrogel was reported where chitosanpolylactide combined with methacrylic anhydride crosslinker undergoes gelation with the application of UV light. ${ }^{114}$ The combination of chitosan and polylactide exploits the biocompatibility and biodegradability of chitosan as well as the control over physical and mechanical properties afforded by highly crystalline polylactide. The hydrogel composition in terms of the density of lactide side chains grafted onto the chitosan backbone as well as the crosslinking density as controlled by UV exposure time resulted in control over hydrogel mechanical properties and degradation rate as well as drug release kinetics. Higher chitosan to lactide ratios and lengthened crosslinking times reduced degradation rates where the effect of crosslinking time had significant effect on model protein release. Longer crosslinking times reduced the burst release of bovine serum albumin and extended the overall period of release. Chitosan-lactide hydrogels were useful to carryout controlled release of BMP-2, which promoted osteogenic differentiation of pre-osteoblastic mouse bone marrow stromal cells in vitro. Overall, injectable, chitosan-based hydrogels that undergo gelation in situ hold significant promise for bone tissue engineering because they provide a suitable environment for encapsulation of cells and/or growth factors and their application to a defect site can occur in a minimally invasive manner. Importantly, hydrogels can be easily combined with bulk, porous scaffolds to yield composite scaffolds that include biological factors.

\subsection{In vivo evaluation of polymer-based composite chitosan scaffolds}

While small animal models are not entirely representative of human physiology, their use represents a necessary step toward evaluation of the bone-regeneration potential of chitosanbased scaffolds in an orthotopic defect site. ${ }^{46,} 152,158-163$ The bone regeneration potential of chitosan-alginate (CA) scaffolds was evaluated with critical size rat calvarial defects. ${ }^{158}$ The experimental groups included (1) an empty control, (2) CA scaffolds and CA scaffolds containing (3) undifferentiated rat MSCs, (4) rat bone marrow aspirate or (5) BMP-2. After 16 weeks, no healing occurred in the empty defect, confirming the critical size nature of the defect. Significant bone formation occurred in all other implant groups as shown in Figure 8. MicroCT imaging and corresponding data indicated that $~ 33 \%$ defect closure occurred in defects filled with CA scaffolds whereas $\sim 71 \%$ closure occurred in defects filled with CA +BMP-2 scaffolds. The ability of CA scaffolds to promote bone regeneration indicates a certain degree of scaffold osteoconductivity although the specific mechanisms that drive this behavior are not clear at this time. Only the CA+BMP-2 group showed mature lamellar bone and bridging trabeculae upon histological evaluation. These results indicate that the osteoconductive nature of CA scaffold is enhanced by the inclusion of osteoinductive cells or growth factors. 


\subsection{Chitosan-calcium phosphate composite scaffolds}

Biphasic calcium phosphate (BCP) is composed of essentially insoluble hydroxyapatite and highly soluble tricalcium phosphate. When exposed to cell culture media, chitosan scaffolds containing BCP microparticles (Figure 9a) were quickly enveloped in a mineral layer on the scaffold surface (Fig. 9b,c). ${ }^{164}$ It is likely that partial dissolution of the BCP microparticles led to reprecipitation of calcium and phosphate ions on the scaffold surface. Compared to pure chitosan scaffolds, chitosan-BCP scaffolds promoted osteogenic activity of MC3T3-E1 cells in terms of cell attachment, morphology, mineralization and expression of marker proteins of osteogenesis (Fig. 9d). In a different study, the incorporation of hydroxyapatite microparticles (microHA) into chitosan-gelatin scaffolds also improved cell-scaffold interactions and osteogenic differentiation potential. ${ }^{136}$ In this case, because HA has very low solubility, the mechanism controlling cell-scaffold interactions is likely different from the BCP microparticle case. However, hydroxyapatite has been shown to adsorb proteins such as fibronectin and vitronectin from serum, which may play a role in enhancing binding and proliferation of MSCs. ${ }^{165}$

Commercially available nanohydroxyapatite (nanoHA) powder has been combined with chitosan to fabricate scaffolds via phase separation. ${ }^{128}$ Enhanced proliferation of MC3T3-E1 pre-osteoblasts was observed on nanoHA-containing composite chitosan scaffolds as compared to pure chitosan scaffolds. Cells attached to composite scaffolds had rough surfaces due to significant accumulation of calcium-rich particles on the cell membrane. This can be attributed to significantly higher mineralization of the composite scaffold. Alternatively, chitosan-nanoHA composites can be fabricated with the HA component formed in situ in chitosan solution. This co-precipitation is a biomimetic process as the mineral phase is formed in association with the polymer phase yielding strong interfacial bonds, similar to physiological mineralization of bone. This approach may be advantageous compared to physical mixing of chitosan with nanoHA, as it may generate a more homogenous distribution of nanoHA throughout the polymer matrix. Mineralization of osteoid involves growth of bioapatite plate-like crystals in the gaps within collagen fibrils as well as in spaces between fibrils. ${ }^{27,} 28$ Collagen fibrils are therefore bridged by areas of mineral, and unfortunately, this process is difficult to mimic.

Hydroxyapatite-chitosan-alginate (HA-CA) scaffolds created through in situ co-precipitation and lyophilization ${ }^{152}$ were placed in $4 \mathrm{~mm}$ critical size mouse calvarial defects for 4 and 8 weeks and compared to control CA scaffolds. After 4 weeks, defects containing HA-CA scaffolds showed low-density mineralization whereas no bone formation was apparent in sites filled with CA scaffolds. After 8 weeks, defects filled with HA-CA scaffolds contained mineralized bone, osteoblasts and osteoclasts, while only low-density mineralization was visible in CA scaffold-filled defects at this later time point. In this case, the presence of nanoscale HA seemingly rendered the scaffolds osteoinductive and allowed for recruitment and differentiation of native MSCs. Overall, the inclusion of nanoHA in the polymer matrix seems to improve chitosan scaffolds in three ways: 1) the response of osteogenic cells is enhanced in terms of cell attachment, proliferation and differentiation, ${ }^{91,128,136,166}$ 2) the scaffold compressive modulus is increased and 3) scaffold swelling is decreased. ${ }^{128,} 167$ The improvement in osteogenic cell response may be related to changes in scaffold surface 
roughness/topography, ${ }^{91}$ enhanced protein binding to nanoHA leading to improved focal adhesion formation, ${ }^{136}$ and/or biological apatite formation facilitated by nanoHA particles acting as nucleation sites. ${ }^{168}$ While modest, increases in scaffold compressive moduli have been reported for chitosan scaffolds containing hydroxyapatite, $89,91,128,169,170$ and some of these scaffolds demonstrate compressive moduli in the range of cancellous bone (Table $1)$.

\subsection{Chitosan-based nanofiber scaffolds}

To incorporate nanoHA particles into chitosan nanofibers, multiple studies have reported successful electrospinning of chitosan-nanoHA fibers using ultrahigh molecular weight PEO as a fiber-forming agent. ${ }^{140-142}$ While the reports showed some aggregation of nanoHA within fibers, the ceramic phase remains crystalline despite the utilization of an acetic acid solvent system for nanofiber preparation (Figure 10). ${ }^{141}$ Composite nanofibrous scaffolds appeared to better support long-term attachment and proliferation of C3H10T1/2 mouse mesenchymal stem cells as compared with pure chitosan scaffolds, and without osteogenic supplementation, expression of osteogenic genes including Col I, Runx2, $A L P$, and $O C$ were all significantly upregulated in MSCs cultured on composite scaffolds. ${ }^{140}$ Because osteogenic media supplementation was not necessary to stimulate expression of markers of osteogenic differentiation, it is likely that the presence of nanoHA imparts osteoinductivity on the scaffold.

Defining and understanding the mechanisms that govern the interactions between osteogenic cells and chitosan-based scaffolds is essential to improving the design of next generation scaffolds that are able to promote efficient and complete bone regeneration in vivo. Initial in vitro studies of rat bone marrow-derived mesenchymal stem cells (BMSCs) seeded on scaffolds composed of chitosan nanofibers and HA particles, investigated the effect of nanofibers and nanoHA on cell shape, proliferation rate, gene expression and alkaline phosphatase activity. ${ }^{46}$ The results showed that scaffolds containing HA, whether micro- or nano-particles, supported a spindle morphology for rat BMSCs, which was in contrast to the spherical morphology adopted by the cells on chitosan nanofiber scaffolds without a calcium phosphate component. This was an indication that the presence of HA supports cell adhesion and spreading. Overall, this study concluded that the scaffolds induced activation of integrins, the BMP signaling pathway and subsequently, osteogenic differentiation of rat BMSCs thus indicating a possible mechanism behind the cell-substrate interactions in this system. Scaffolds were also loaded with rat BMSCs and used to fill critical size rat calvarial defects. Compared to other experimental groups (chitosan nanofiber scaffolds with cells and nanoHA/chitosan nanofiber scaffolds without cells), scaffolds with BMSCs promoted largearea bone regeneration within the defect site. The role of BMSCs in bone regeneration could be attributed to 1) their differentiation into bone-forming osteoblasts and/or 2) their release of trophic factors that promote recruitment and differentiation of native MSCs.

\subsection{Enhanced functionality of chitosan-based scaffolds}

The presence of micro- or nanoscale calcium phosphate particles in chitosan scaffolds provides important functionalities as described above, but the incorporation or immobilization of a second or even third functional component can further improve bone 
tissue engineering scaffolds for clinical use. A recent study describes the enzymaticallyassisted co-precipitation of amorphous calcium phosphate and the antibiotic ciprofloxacin within a chitosan solution. ${ }^{171}$ The composite polymeric solution was then subject to a unidirectional freeze-drying process known as ice segregation induced self-assembly (ISISA) to form porous scaffolds. Ciprofloxacin precipitation resulted in needle-like crystals with granular aggregates of amorphous calcium phosphate on the crystal surfaces as shown in Figure 11. Amorphous calcium phosphate is significantly more soluble than hydroxyapatite and therefore its dissolution into calcium and phosphate ions can promote scaffold biomineralization and possibly osteoinductivity. The ciprofloxacin component may be very useful for combatting possible post-surgical infections following scaffold implantation. Rational design of multifunctional, multicomponent biomaterials that address more than one aspect of the bone regeneration process is an important step toward clinicallyrelevant and useful synthetic bone grafts.

A critical property of functional chitosan-based scaffolds is osteoinductivity or the ability of the scaffold to recruit and induce differentiation of mesenchymal stem cells into boneforming osteoblasts. While mesenchymal stem cells may respond positively to a scaffold in vitro in terms of adhesion, proliferation and even differentiation in the presence of media with osteogenic supplements, the end goal of bone tissue engineering is to promote efficient and complete bone regeneration in a defect in vivo. Osteoinductivity can be imparted on chitosan-based scaffolds by incorporating calcium phosphates that dissolve and reprecipitate to yield a biological apatite layer or through the incorporation and subsequent delivery of growth factors such as BMP-2. While growth factors are often combined with chitosanbased scaffolds through physical entrapment and released via diffusion, the amount of growth factor needed to elicit a biological response is often at supraphysiologic levels. In addition, there is often an issue with a burst release of the growth factor. An alternative approach for growth factor delivery is to mimick non-covalent growth factor-extracellular matrix interactions. Heparin, an anionic glycosaminoglycan, plays a role in modulating the activity of growth factors such as bone morphogenetic proteins via non-covalent interactions ${ }^{172}$ and this type of relationship can be exploited for improving chitosan-based scaffolds. For example, heparin has been covalently conjugated to chitosan-alginate PECs used for drug delivery. ${ }^{173}$ When the PECs were exposed to basic fibroblastic growth factor (FGF-2), the presence of heparin and its interaction with FGF-2 acted to localize the growth factor activity and significantly slow its release.

Heparin has been both covalently and non-covalently (via electrostatic interactions) immobilized on porous chitosan scaffolds for bone tissue engineering applications. In vitro results demonstrated that chitosan scaffolds functionalized with heparin had a significant positive effect on the differentiation of MC3T3-E1 pre-osteoblast cells in terms of enhanced alkaline phosphatase activity and osteocalcin expression as compared with chitosan scaffolds without heparin. ${ }^{174}$ The mechanism of action here is likely the sequestration of cell-secreted BMPs by heparin thus promoting localization of the growth factor and thereby facilitating osteogenic differentiation. The non-covalent immobilization of heparin onto microsphere-based chitosan-poly(lactide-co-glycolide) (PLGA) scaffolds via electrostatic interactions allowed for subsequent immobilization of BMP-2 in a manner that mimicks 
non-covalent growth factor-ECM interactions. ${ }^{155}$ These scaffolds were applied to the rabbit ulnar critical-sized defect model and the presence of heparin and BMP-2 resulted in early bone formation compared to the other experimental groups (6 week time point) as well as complete bridging of the defect on the radial side at 12 weeks. In that study, scaffolds were exposed to a BMP-2 solution to promote its immobilization, but functionalization of chitosan-based scaffolds with heparin and heparan sulfate glycosaminoglycans may also be very useful for sequestration of endogenous growth factors in vivo in support of bone regeneration. ${ }^{175}$

\section{Conclusions}

Bone tissue engineering is regarded as an alternative approach to autograft and allograft for the treatment of bone lost to trauma or disease. Recent years have witnessed intensified efforts in developing chitosan scaffolds and their application in the field of bone tissue engineering due to its minimal foreign body response, intrinsic antibacterial nature, biocompatibility, biodegradability, and ease of manufacturing. A variety of methods have been introduced for fabrication of chitosan scaffolds with highly interconnected porous structure and pore diameters suitable for cell ingrowth and bone formation. Pure chitosan is a suitable substrate for adhesion and proliferation of osteoblasts as well as matrix formation and mineralization, but the strength and structural stability of pure chitosan scaffolds is inadequate for bone tissue engineering applications. Composite chitosan scaffolds, which incorporate other biocompatible polymers and/or micro- or nanoscale calcium phosphates, usually possess mechanical and biological properties superior to pure chitosan scaffolds. While advances have been made in improving the compressive strength of pure chitosan scaffolds, the incorporation of a second component such as alginate and/or nanohydroxyapatite seems to show substantial improvement in scaffold structural stability and osteogenic response. Overall, chitosan combined with bioactive ceramics have been found to have a predominant role in bone tissue engineering in recent years as these composites exhibit tailored physical, biological and mechanical properties favorable for bone regeneration as well as predictable degradation behavior.

Collectively, the studies described in this review show that significant progress has been made toward the design of chitosan-based scaffolds with an underlying theme of biomimetics. Dissolution and reprecipitation of some synthetic calcium phosphate scaffold components can result in the formation of a biologically relevant mineral or apatite layer on scaffold surfaces that can improve cell-scaffold interactions. In vivo, this bioapatite layer may co-precipitate with relevant growth factors resulting in an osteoinductive environment. Chitosan nanofibers are similar in shape and scale to structural proteins such as collagen present in bone matrix. The in situ precipitation of nanohydroxyapatite within a chitosan solution allows for the formation of nanofibers with closely associated mineral particles similar to bone tissue, and nanoHA has been associated with improvements in mesenchymal stem cell spreading and osteogenic differentiation. Mesenchymal stem cells introduced into a defect site may either actively participate in bone formation by synthesizing mineralized matrix or secrete trophic factors that activate endogenous cells. Heparin can be immobilized on chitosan scaffolds as a way to exploit naturally-occurring non-covalent interactions between growth factors and extracellular matrix components. This approach may be very 
useful for sequestration of endogenous growth factors in situ in a defect site as opposed to delivery of supraphysiological doses of growth factors as a common practice in tissue engineering research today.

Although many composite chitosan scaffolds have been developed, there remain significant challenges in constructing effective chitosan-based scaffolds such as insufficient mechanical strength, poor batch-to-batch reproducibility, ineffective delivery of growth factors, and poor vascularization. Even though ceramic nanoparticles have tremendous mechanical strength and are biomimetic in terms of natural bone structure when dispersed within a polymer phase, the uniform dispersion of nanoparticles in chitosan matrix can be difficult. Commercially available chitosan materials represent a source of inconsistency related to the properties of chitosan scaffolds. Clinical grade chitosan materials with well-defined molecular weights and the degrees of deacetylation are highly recommended for all in vivo studies so that the results from various labs can be fairly compared and analyzed. Bone is highly vascularized and the performance of a bone scaffold is dictated by its ability to induce the formation of new blood vessels in support of tissue regeneration. Vascularization of chitosan-based scaffolds can be improved by effective delivery of growth factors such as vascular endothelial growth factor (VEGF) and/or platelet-derived growth factor (PDGF) or the incorporation of cells that participate in angiogenesis or vasculogenesis. Scaffolds with multi-scale porosity may also improve scaffold vascularization as small and large pores are favorable, respectively, for angiogenesis and bone ingrowth. Overall the design and implantation of truly effective bone tissue engineering scaffolds remains a challenge, but chitosan is an effective base material which can be combined with other materials and biological factors to yield promising constructs for bone regeneration.

\section{Acknowledgments}

This work was supported in part by NIH grant R01CA172455, Washington Research Foundation gift, and Kyocera Professorship Endowment. Dr. Levengood acknowledges the support from the Ruth L. Kirschstein NIH Training grant T32CA138312.

\section{References}

1. Greenwald, AS.; Boden, SD.; Goldberg, VM.; Yaszemski, M.; Heim, CS. presented in part at the American Academy of Orthopaedic Surgeons; Chicago, IL. March 22-26, 2006; 2006.

2. Jahangir AA, Nunley RM, S. M, Sharan A. Journal of the American Academy of Orthopaedic Surgeons. 2008; 2

3. Amini AR, Laurencin CT, Nukavarapu SP. Critical reviews in biomedical engineering. 2012; 40:363-408. [PubMed: 23339648]

4. Betz RR. Orthopedics. 2002; 25:s561-570. [PubMed: 12038843]

5. Khan Y, Yaszemski MJ, Mikos AG, Laurencin CT. J Bone Joint Surg Am. 2008; 90(Suppl 1):3642. [PubMed: 18292355]

6. Silber JS, Anderson DG, Daffner SD, Brislin BT, Leland JM, Hilibrand AS, Vaccaro AR, Albert TJ. Spine (Phila Pa 1976). 2003; 28:134-139. [PubMed: 12544929]

7. Wheeler DL, Enneking WF. Clin Orthop Relat Res. 2005 DOI: 00003086-200506000-00008 [pii], 36-42.

8. Fielding G, Bose S. Acta Biomater. 2013; 9:9137-9148. [PubMed: 23871941]

9. Pawlik J, Widziolek M, Cholewa-Kowalska K, Laczka M, Osyczka AM. J Biomed Mater Res A. 2013 DOI: 10.1002/jbm.a.34903. 
10. Sowjanya JA, Singh J, Mohita T, Sarvanan S, Moorthi A, Srinivasan N, Selvamurugan N. Colloids Surf B Biointerfaces. 2013; 109:294-300. [PubMed: 23668983]

11. Tiainen H, Wohlfahrt JC, Verket A, Lyngstadaas SP, Haugen HJ. Acta Biomater. 2012; 8:23842391. [PubMed: 22395069]

12. Vallet-Regi M, Ruiz-Hernandez E. Adv Mater. 2011; 23:5177-5218. [PubMed: 22009627]

13. Oh SH, Park IK, Kim JM, Lee JH. Biomaterials. 2007; 28:1664-1671. [PubMed: 17196648]

14. Roosa SM, Kemppainen JM, Moffitt EN, Krebsbach PH, Hollister SJ. J Biomed Mater Res A. 2010; 92:359-368. [PubMed: 19189391]

15. Holland TA, Mikos AG. Adv Biochem Eng Biotechnol. 2006; 102:161-185. [PubMed: 17089790]

16. Shen H, Hu X, Yang F, Bei J, Wang S. Biomaterials. 2009; 30:3150-3157. [PubMed: 19232709]

17. Swetha M, Sahithi K, Moorthi A, Srinivasan N, Ramasamy K, Selvamurugan N. Int J Biol Macromol. 2010; 47:1-4. [PubMed: 20361991]

18. Bhattarai N, Edmondson D, Veiseh O, Matsen FA, Zhang M. Biomaterials. 2005; 26:6176-6184. [PubMed: 15885770]

19. Jayakumar R, Prabaharan M, Nair SV, Tamura H. Biotechnology advances. 2010; 28:142-150. [PubMed: 19913083]

20. Kim IY, Seo SJ, Moon HS, Yoo MK, Park IY, Kim BC, Cho CS. Biotechnology advances. 2008; 26:1-21. [PubMed: 17884325]

21. Lee KY, Jeong L, Kang YO, Lee SJ, Park WH. Adv Drug Deliv Rev. 2009; 61:1020-1032. [PubMed: 19643155]

22. Seol YJ, Lee JY, Park YJ, Lee YM, Young K, Rhyu IC, Lee SJ, Han SB, Chung CP. Biotechnol Lett. 2004; 26:1037-1041. [PubMed: 15218375]

23. Muzzarelli RA, Mattioli-Belmonte M, Tietz C, Biagini R, Ferioli G, Brunelli MA, Fini M, Giardino R, Ilari P, Biagini G. Biomaterials. 1994; 15:1075-1081. [PubMed: 7888578]

24. Venkatesan J, Kim SK. Marine drugs. 2010; 8:2252-2266. [PubMed: 20948907]

25. Fratzl P. Nat Mater. 2008; 7:610-612. [PubMed: 18654582]

26. Sommerfeldt DW, Rubin CT. Eur Spine J. 2001; 10(Suppl 2):S86-95. [PubMed: 11716022]

27. Beniash E. Wiley Interdiscip Rev Nanomed Nanobiotechnol. 2011; 3:47-69. [PubMed: 20827739]

28. Weiner S, Traub W. FASEB J. 1992; 6:879-885. [PubMed: 1740237]

29. Anderson HC. Curr Rheumatol Rep. 2003; 5:222-226. [PubMed: 12744815]

30. Robling AG, Turner CH. Crit Rev Eukaryot Gene Expr. 2009; 19:319-338. [PubMed: 19817708]

31. Schaffler MB, Cheung WY, Majeska R, Kennedy O. Calcif Tissue Int. 2013 DOI: 10.1007/ s00223-013-9790-y.

32. Davies, JE.; Hosseini, MM. Bone engineering. Davies, JE., editor. em squared Inc.; Toronto: 2000.

33. LeGeros RZ. Chem Rev. 2008; 108:4742-4753. [PubMed: 19006399]

34. Hollister SJ. Nat Mater. 2005; 4:518-524. [PubMed: 16003400]

35. Boyan BD, Bonewald LF, Paschalis EP, Lohmann CH, Rosser J, Cochran DL, Dean DD, Schwartz Z, Boskey AL. Calcif Tissue Int. 2002; 71:519-529. [PubMed: 12232675]

36. Hing KA, Annaz B, Saeed S, Revell PA, Buckland T. J Mater Sci Mater Med. 2005; 16:467-475. [PubMed: 15875258]

37. Venugopal J, Prabhakaran MP, Zhang Y, Low S, Choon AT, Ramakrishna S. Philos Trans A Math Phys Eng Sci. 2010; 368:2065-2081. [PubMed: 20308115]

38. Wagoner Johnson AJ, Herschler BA. Acta Biomater. 2011; 7:16-30. [PubMed: 20655397]

39. Ramay HR, Zhang M. Biomaterials. 2004; 25:5171-5180. [PubMed: 15109841]

40. Rohl L, Larsen E, Linde F, Odgaard A, Jorgensen J. J Biomech. 1991; 24:1143-1149. [PubMed: 1769979]

41. Madihally SV, Matthew HW. Biomaterials. 1999; 20:1133-1142. [PubMed: 10382829]

42. Aydin HM, El Haj AJ, Piskin E, Yang Y. J Tissue Eng Regen Med. 2009; 3:470-476. [PubMed: 19530258]

43. Costa-Pinto AR, Reis RL, Neves NM. Tissue Eng Part B Rev. 2011; 17:331-347. [PubMed: 21810029] 
44. Di Martino A, Sittinger M, Risbud MV. Biomaterials. 2005; 26:5983-5990. [PubMed: 15894370]

45. Wu L, Ding J. Biomaterials. 2004; 25:5821-5830. [PubMed: 15172494]

46. Liu H, Peng H, Wu Y, Zhang C, Cai Y, Xu G, Li Q, Chen X, Ji J, Zhang Y, OuYang HW. Biomaterials. 2013; 34:4404-4417. [PubMed: 23515177]

47. Habibovic P, de Groot K. J Tissue Eng Regen Med. 2007; 1:25-32. [PubMed: 18038389]

48. Habibovic P, Yuan H, van der Valk CM, Meijer G, van Blitterswijk CA, de Groot K. Biomaterials. 2005; 26:3565-3575. [PubMed: 15621247]

49. Gosain AK, Song L, Riordan P, Amarante MT, Nagy PG, Wilson CR, Toth JM, Ricci JL. Plast Reconstr Surg. 2002; 109:619-630. [PubMed: 11818845]

50. Ducheyne P, Qiu Q. Biomaterials. 1999; 20:2287-2303. [PubMed: 10614935]

51. Muller P, Bulnheim U, Diener A, Luthen F, Teller M, Klinkenberg ED, Neumann HG, Nebe B, Liebold A, Steinhoff G, Rychly J. J Cell Mol Med. 2008; 12:281-291. [PubMed: 18366455]

52. Pillai CKS, Paul W, Sharma CP. Progress in Polymer Science. 2009; 34:641-678.

53. Mao S, Sun W, Kissel T. Adv Drug Deliv Rev. 2010; 62:12-27. [PubMed: 19796660]

54. Illum L, Jabbal-Gill I, Hinchcliffe M, Fisher AN, Davis SS. Adv Drug Deliv Rev. 2001; 51:81-96. [PubMed: 11516781]

55. Amidi M, Mastrobattista E, Jiskoot W, Hennink WE. Adv Drug Deliv Rev. 2010; 62:59-82. [PubMed: 19925837]

56. Senel S, McClure SJ. Adv Drug Deliv Rev. 2004; 56:1467-1480. [PubMed: 15191793]

57. Aranaz I, Mengibar M, Harris R, Panos I, Miralles B, Acosta N, Galed G, Heras A. Current Chemical Biology. 2009; 3:203-230.

58. Li J, Du Y, Liang H. Polymer Degradation. 2007; 92:515-524.

59. Jana S, Florczyk SJ, Leung M, Zhang MQ. J Mater Chem. 2012; 22:6291-6299.

60. Ueno H, Mori T, Fujinaga T. Adv Drug Deliv Rev. 2001; 52:105-115. [PubMed: 11718934]

61. Dai T, Tanaka M, Huang YY, Hamblin MR. Expert review of anti-infective therapy. 2011; 9:857879. [PubMed: 21810057]

62. Kim IS, Park JW, Kwon IC, Baik BS, Cho BC. Plast Reconstr Surg. 2002; 109:1966-1977. [PubMed: 11994601]

63. Klokkevold PR, Vandemark L, Kenney EB, Bernard GW. Journal of periodontology. 1996; 67:1170-1175. [PubMed: 8959566]

64. Yang X, Chen X, Wang H. Biomacromolecules. 2009; 10:2772-2778. [PubMed: 19743842]

65. Mathews S, Gupta PK, Bhonde R, Totey S. Cell proliferation. 2011; 44:537-549. [PubMed: 22011046]

66. VandeVord PJ, Matthew HW, DeSilva SP, Mayton L, Wu B, Wooley PH. J Biomed Mater Res. 2002; 59:585-590. [PubMed: 11774317]

67. Zhang Y, Zhang M. J Mater Sci Mater Med. 2004; 15:255-260. [PubMed: 15334997]

68. Kavya KC, Jayakumar R, Nair S, Chennazhi KP. Int J Biol Macromol. 2013; 59:255-263. [PubMed: 23591473]

69. Park H, Choi B, Nguyen J, Fan J, Shafi S, Klokkevold P, Lee M. Carbohydr Polym. 2013; 97:587596. [PubMed: 23911489]

70. Annabi N, Nichol JW, Zhong X, Ji C, Koshy S, Khademhosseini A, Dehghani F. Tissue Eng Part B Rev. 2010; 16:371-383. [PubMed: 20121414]

71. Lim JI, Lee YK, Shin JS, Lim KJ. J Biomater Sci Polym Ed. 2010 DOI: jbs3168 [pii] 10.1163/092050610X504783.

72. Ma J, Wang H, He B, Chen J. Biomaterials. 2001; 22:331-336. [PubMed: 11205436]

73. Yu H, Matthew HW, Wooley PH, Yang SY. J Biomed Mater Res B Appl Biomater. 2008; 86:541547. [PubMed: 18335434]

74. Draghi L, Resta S, Pirozzolo MG, Tanzi MC. J Mater Sci Mater Med. 2005; 16:1093-1097. [PubMed: 16362206]

75. Zhang J, Wu L, Jing D, Ding J. Polymer. 2005; 46:4979-4985.

76. Ju YM, Park K, Son JS, Kim JJ, Rhie JW, Han DK. J Biomed Mater Res B Appl Biomater. 2008; 85:252-260. [PubMed: 17973245] 
77. Nam YS, Yoon JJ, Park TG. J Biomed Mater Res. 2000; 53:1-7. [PubMed: 10634946]

78. Ji C, Annabi N, Khademhosseini A, Dehghani F. Acta Biomater. 2011; 7:1653-1664. [PubMed: 21130905]

79. Mooney DJ, Baldwin DF, Suh NP, Vacanti JP, Langer R. Biomaterials. 1996; 17:1417-1422. [PubMed: 8830969]

80. Yoon, DM.; Fisher, JP. Biomedical Materials. Narayan, R., editor. Springer; 2009.

81. Ji C, Annabi N, Hosseinkhani M, Sivaloganathan S, Dehghani F. Acta Biomater. 2012; 8:570-578. [PubMed: 21996623]

82. Tai H, Mather ML, Howard D, Wang W, White LJ, Crowe JA, Morgan SP, Chandra A, Williams DJ, Howdle SM, Shakesheff KM. European cells \& materials. 2007; 14:64-77. [PubMed: 18085505]

83. Ho MH, Kuo PY, Hsieh HJ, Hsien TY, Hou LT, Lai JY, Wang DM. Biomaterials. 2004; 25:129_ 138. [PubMed: 14580916]

84. Cruz DM, Gomes M, Reis RL, Moratal D, Salmeron-Sanchez M, Ribelles JL, Mano JF. J Biomed Mater Res A. 2010; 95:1182-1193. [PubMed: 20925083]

85. Hsieh CY, Tsai SP, Ho MH, Wang DM, Liu CE, Hsieh CH, Tseng HC, Hsieh HJ. Carbohydr Polym. 2007; 67:124-132.

86. Lantada AD, Morgado PL. Annu Rev Biomed Eng. 2012; 14:73-96. [PubMed: 22524389]

87. Manjubala I, Scheler S, Bossert J, Jandt KD. Acta Biomater. 2006; 2:75-84. [PubMed: 16701861]

88. Jiankang H, Dichen L, Yaxiong L, Bo Y, Hanxiang Z, Qin L, Bingheng L, Yi L. Acta Biomater. 2009; 5:453-461. [PubMed: 18675601]

89. Li L, Li B, Zhao M, Ding S, Zhou C. J Biomed Mater Res B Appl Biomater. 2011; 98:230-237. [PubMed: 21681952]

90. Deshmukh TR, Kuthe AM, Chaware SM, Bagaria V, Ingole DS. Comput Methods Biomech Biomed Engin. 2012; 15:363-370. [PubMed: 22414075]

91. Chesnutt BM, Viano AM, Yuan Y, Yang Y, Guda T, Appleford MR, Ong JL, Haggard WO, Bumgardner JD. J Biomed Mater Res A. 2009; 88:491-502. [PubMed: 18306307]

92. Jiang T, Abdel-Fattah WI, Laurencin CT. Biomaterials. 2006; 27:4894-4903. [PubMed: 16762408]

93. Sinha VR, Singla AK, Wadhawan S, Kaushik R, Kumria R, Bansal K, Dhawan S. Int J Pharm. 2004; 274:1-33. [PubMed: 15072779]

94. Malafaya PB, Oliveira JT, Reis RL. Tissue Eng Part A. 2010; 16:735-747. [PubMed: 19772454]

95. Jiang T, Khan Y, Nair LS, Abdel-Fattah WI, Laurencin CT. J Biomed Mater Res A. 2010; 93:1193-1208. [PubMed: 19777575]

96. Cassella JP, Barber P, Catterall AC, Ali SY. Bone. 1994; 15:329-334. [PubMed: 8068454]

97. Zhao J, Han W, Chen H, Tu M, Huan S, Miao G, Zeng R, Wu H, Cha Z, Zhou C. J Mater Sci Mater Med. 2012; 23:517-525. [PubMed: 22042464]

98. Antony MJ, Jayakannan M. J Phys Chem B. 2010; 114:1314-1324. [PubMed: 20050618]

99. Jin J, Hassanzadeh P, Perotto G, Sun W, Brenckle MA, Kaplan D, Omenetto FG, Rolandi M. Adv Mater. 2013; 25:4482-4487. [PubMed: 23788326]

100. Jayaraman K, Kotaki M, Zhang Y, Mo X, Ramakrishna S. J Nanosci Nanotechnol. 2004; 4:5265. [PubMed: 15112541]

101. Pati F, Adhikari B, Dhara S. Carbohydrate Research. 2011; 346:2582-2588. [PubMed: 21962591]

102. Pati F, Kalita H, Adhikari B, Dhara S. J Biomed Mater Res A. 2013; 101:2526-2537. [PubMed: 23359556]

103. Geng X, Kwon OH, Jang J. Biomaterials. 2005; 26:5427-5432. [PubMed: 15860199]

104. Ohkawa K, Cha D, Kim H, Nishida A, Yamamoto H. Macromolecular Rapid Communications. 2004; 25:1600-1605.

105. Dahlin RL, Kasper FK, Mikos AG. Tissue Eng Part B Rev. 2011; 17:349-364. [PubMed: 21699434]

106. Kai D, Jin G, Prabhakaran MP, Ramakrishna S. Biotechnology journal. 2013; 8:59-72. [PubMed: 23139231] 
107. Homayoni H, Ravandi SAH, Valizadeh M. Carbohydrate Polymers. 2009; 77:565-661.

108. Ramakrishna S, F. K, Teo W, Yong T, Ma Z, Ramaseshan R. Materials Today. 2006; 9

109. Pham QP, Sharma U, Mikos AG. Tissue engineering. 2006; 12:1197-1211. [PubMed: 16771634]

110. Bhattarai N, Gunn J, Zhang M. Adv Drug Deliv Rev. 2010; 62:83-99. [PubMed: 19799949]

111. Ladet S, David L, Domard A. Nature. 2008; 452:76-79. [PubMed: 18322531]

112. Ahmadi R, de Bruijn JD. J Biomed Mater Res A. 2008; 86:824-832. [PubMed: 18041728]

113. Liao HT, Chen CT, Chen JP. Tissue Eng Part C Methods. 2011; 17:1139-1149. [PubMed: 21870942]

114. Kim S, Kang Y, Mercado-Pagan AE, Maloney WJ, Yang Y. J Biomed Mater Res B Appl Biomater. 2014 DOI: 10.1002/jbm.b.33118.

115. Jo S, Kim S, Cho TH, Shin E, Hwang SJ, Noh I. J Biomed Mater Res A. 2013; 101:892-901. [PubMed: 23023810]

116. Cao L, Werkmeister JA, Wang J, Glattauer V, McLean KM, Liu C. Biomaterials. 2014; 35:27302742. [PubMed: 24438908]

117. Wise JK, Alford AI, Goldstein SA, Stegemann JP. Tissue Eng Part A. 2014; 20:210-224. [PubMed: 23879621]

118. Dyondi D, Webster TJ, Banerjee R. Int J Nanomedicine. 2013; 8:47-59. [PubMed: 23293519]

119. Bhattarai N, Matsen FA, Zhang M. Macromol Biosci. 2005; 5:107-111. [PubMed: 15719428]

120. Niranjan R, Koushik C, Saravanan S, Moorthi A, Vairamani M, Selvamurugan N. Int J Biol Macromol. 2013; 54:24-29. [PubMed: 23201776]

121. Correlo VM, Boesel LF, Pinho E, Costa-Pinto AR, Alves da Silva ML, Bhattacharya M, Mano JF, Neves NM, Reis RL. J Biomed Mater Res A. 2009; 91:489-504. [PubMed: 18985771]

122. Costa-Pinto AR, Correlo VM, Sol PC, Bhattacharya M, Charbord P, Delorme B, Reis RL, Neves NM. Biomacromolecules. 2009; 10:2067-2073. [PubMed: 19621927]

123. Costa-Pinto AR, Salgado AJ, Correlo VM, Sol P, Bhattacharya M, Charbord P, Reis RL, Neves NM. Tissue Eng Part A. 2008; 14:1049-1057. [PubMed: 19230127]

124. Oliveira JT, Correlo VM, Sol PC, Costa-Pinto AR, Malafaya PB, Salgado AJ, Bhattacharya M, Charbord P, Neves NM, Reis RL. Tissue Eng Part A. 2008; 14:1651-1661. [PubMed: 18611147]

125. Li Z, Ramay HR, Hauch KD, Xiao D, Zhang M. Biomaterials. 2005; 26:3919-3928. [PubMed: 15626439]

126. Mao JS, Zhao LG, Yin YJ, Yao KD. Biomaterials. 2003; 24:1067-1074. [PubMed: 12504529]

127. Miranda SC, Silva GA, Hell RC, Martins MD, Alves JB, Goes AM. Arch Oral Biol. 2011; 56:115. [PubMed: 20887975]

128. Thein-Han WW, Misra RD. Acta Biomater. 2009; 5:1182-1197. [PubMed: 19121983]

129. Thein-Han WW, Saikhun J, Pholpramoo C, Misra RD, Kitiyanant Y. Acta Biomater. 2009; 5:3453-3466. [PubMed: 19460465]

130. Huang Y, Onyeri S, Siewe M, Moshfeghian A, Madihally SV. Biomaterials. 2005; 26:76167627. [PubMed: 16005510]

131. Barrere F, van Blitterswijk CA, de Groot K. Int J Nanomedicine. 2006; 1:317-332. [PubMed: 17717972]

132. Yuan H, Fernandes H, Habibovic P, de Boer J, Barradas AM, de Ruiter A, Walsh WR, van Blitterswijk CA, de Bruijn JD. Proc Natl Acad Sci U S A. 2010; 107:13614-13619. [PubMed: 20643969]

133. Suarez-Gonzalez D, Lee JS, Lan Levengood SK, Vanderby R Jr. Murphy WL. Acta Biomater. 2012; 8:1117-1124. [PubMed: 22154864]

134. Zhu P, Masuda Y, Koumoto K. Biomaterials. 2004; 25:3915-3921. [PubMed: 15020168]

135. Zhang Y, Zhang M. J Biomed Mater Res. 2001; 55:304-312. [PubMed: 11255183]

136. Zhao F, Grayson WL, Ma T, Bunnell B, Lu WW. Biomaterials. 2006; 27:1859-1867. [PubMed: 16225916]

137. Kong L, Gao Y, Cao W, Gong Y, Zhao N, Zhang X. J Biomed Mater Res A. 2005; 75:275-282. [PubMed: 16044404] 
138. Li Z, Yubao L, Aiping Y, Xuelin P, Xuejiang W, Xiang Z. J Mater Sci Mater Med. 2005; 16:213219. [PubMed: 15744612]

139. Rusu VM, Ng CH, Wilke M, Tiersch B, Fratzl P, Peter MG. Biomaterials. 2005; 26:5414-5426. [PubMed: 15814140]

140. Zhang Y, Reddy VJ, Wong SY, Li X, Su B, Ramakrishna S, Lim CT. Tissue Eng Part A. 2010; 16:1949-1960. [PubMed: 20088700]

141. Zhang Y, Venugopal JR, El-Turki A, Ramakrishna S, Su B, Lim CT. Biomaterials. 2008; 29:4314-4322. [PubMed: 18715637]

142. Peng H, Yin Z, Liu H, Chen X, Feng B, Yuan H, Su B, Ouyang H, Zhang Y. Nanotechnology. 2012; 23:485102. [PubMed: 23128604]

143. Hsu YY, Gresser JD, Trantolo DJ, Lyons CM, Gangadharam PR, Wise DL. J Biomed Mater Res. 1997; 35:107-116. [PubMed: 9104703]

144. Zhang R, Ma PX. J Biomed Mater Res. 1999; 44:446-455. [PubMed: 10397949]

145. Tully-Dartez S, Cardenas HE, Sit PF. Tissue Eng Part C Methods. 2010; 16:339-345. [PubMed: 19580421]

146. Berger J, Reist M, Mayer JM, Felt O, Peppas NA, Gurny R. Eur J Pharm Biopharm. 2004; 57:19_ 34. [PubMed: 14729078]

147. Goldstein SA. J Biomech. 1987; 20:1055-1061. [PubMed: 3323197]

148. Lian JB, Stein GS. Critical reviews in oral biology. 1992; 3:269-305.

149. Golub EE, Boesze-Battaglia K. Clin Opin Orthop. 2007; 18:444-448.

150. Yin Y, Ye F, Cui J, Zhang F, Li X, Yao K. J Biomed Mater Res A. 2003; 67:844-855. [PubMed: 14613233]

151. Oliveira JM, Kotobuki N, Tadokoro M, Hirose M, Mano JF, Reis RL, Ohgushi H. Bone. 2010; 46:1424-1435. [PubMed: 20152952]

152. Jin HH, Kim DH, Kim TW, Shin KK, Jung JS, Park HC, Yoon SY. Int J Biol Macromol. 2012; 51:1079-1085. [PubMed: 22959955]

153. Dellinger JG, Eurell JA, Stewart M, Jamison RD. J Biomed Mater Res A. 2006; 76:366-376. [PubMed: 16270335]

154. Woodard JR, Hilldore AJ, Lan SK, Park CJ, Morgan AW, Eurell JA, Clark SG, Wheeler MB, Jamison RD, Wagoner Johnson AJ. Biomaterials. 2007; 28:45-54. [PubMed: 16963118]

155. Jiang T, Nukavarapu SP, Deng M, Jabbarzadeh E, Kofron MD, Doty SB, Abdel-Fattah WI, Laurencin CT. Acta Biomater. 2010; 6:3457-3470. [PubMed: 20307694]

156. Lu Y, Lee JS, Nemke B, Graf BK, Royalty K, Illgen R 3rd, Vanderby R Jr. Markel MD, Murphy WL. PloS one. 2012; 7:e50378. [PubMed: 23185610]

157. Lan Levengood SK, Polak SJ, Wheeler MB, Maki AJ, Clark SG, Jamison RD, Wagoner Johnson AJ. Biomaterials. 2010; 31:3552-3563. [PubMed: 20153042]

158. Florczyk SJ, Leung M, Li Z, Huang JI, Hopper RA, Zhang M. J Biomed Mater Res A. 2013; 101:2974-2983. [PubMed: 23737120]

159. Costa-Pinto AR, Correlo VM, Sol PC, Bhattacharya M, Srouji S, Livne E, Reis RL, Neves NM. J Tissue Eng Regen Med. 2012; 6:21-28. [PubMed: 21312336]

160. Danilchenko SN, Kalinkevich OV, Pogorelov MV, Kalinkevich AN, Sklyar AM, Kalinichenko TG, Ilyashenko VY, Starikov VV, Bumeyster VI, Sikora VZ, Sukhodub LF. J Biomed Mater Res A. 2011; 96:639-647. [PubMed: 21268238]

161. Kong L, Ao Q, Wang A, Gong K, Wang X, Lu G, Gong Y, Zhao N, Zhang X. J Biomater Appl. 2007; 22:223-239. [PubMed: 17255157]

162. Shi S, Cheng X, Wang J, Zhang W, Peng L, Zhang Y. J Biomater Appl. 2009; 23:331-346. [PubMed: 18667455]

163. Zhang Y, Shi B, Li C, Wang Y, Chen Y, Zhang W, Luo T, Cheng X. J Control Release. 2009; 136:172-178. [PubMed: 19250951]

164. Sendemir-Urkmez A, Jamison RD. J Biomed Mater Res A. 2007; 81:624-633. [PubMed: 17187398] 
165. Wang J, Zhang H, Zhu X, Fan H, Fan Y, Zhang X. J Biomed Mater Res B Appl Biomater. 2013; 101:1069-1077. [PubMed: 23559460]

166. Peter M, Ganesh N, Selvamurugan N, Nair SV, Furuike T, Tamura H, Jayakumar R. Carbohydr Polym. 2010; 80:687-694.

167. Hu Q, Li B, Wang M, Shen J. Biomaterials. 2004; 25:779-785. [PubMed: 14609666]

168. Chen JD, Wang Y, Chen X. J Biomater Sci Polym Ed. 2009; 20:1555-1565. [PubMed: 19619396]

169. Beskardes IG, Demirtas TT, Durukan MD, Gumusderelioglu M. J Tissue Eng Regen Med. 2012 DOI: $10.1002 /$ term.1677.

170. Li LH, Kommareddy KP, Pilz C, Zhou CR, Fratzl P, Manjubala I. Acta Biomater. 2010; 6:25252531. [PubMed: 19398393]

171. Nardecchia S, Gutierrez MC, Serrano MC, Dentini M, Barbetta A, Ferrer ML, del Monte F. Langmuir. 2012; 28:15937-15946. [PubMed: 23088184]

172. Hudalla GA, Murphy WL. Advanced functional materials. 2011; 21:1754-1768. [PubMed: 21921999]

173. Ho YC, Mi FL, Sung HW, Kuo PL. Int J Pharm. 2009; 376:69-75. [PubMed: 19450670]

174. Gumusderelioglu M, Aday S. Carbohydr Res. 2011; 346:606-613. [PubMed: 21333274]

175. Hudalla GA, Kouris NA, Koepsel JT, Ogle BM, Murphy WL. Integrative biology : quantitative biosciences from nano to macro. 2011; 3:832-842. [PubMed: 21720642]

176. Lee JW, Kim KJ, Kang KS, Chen S, Rhie JW, Cho DW. J Biomed Mater Res A. 2013; 101:1865-1875. [PubMed: 23184413]

177. Yang F, Wang J, Hou J, Guo H, Liu C. Biomaterials. 2013; 34:1514-1528. [PubMed: 23187021]

178. Zong C, Xue D, Yuan W, Wang W, Shen D, Tong X, Shi D, Liu L, Zheng Q, Gao C, Wang J. European cells \& materials. 2010; 20:109-120. [PubMed: 21249628]

179. Tanaka T, Hirose M, Kotobuki N, Tadokoro M, Ohgushi H, Fukuchi T, Sato J, Seto K. J Biomed Mater Res A. 2009; 91:428-435. [PubMed: 18985782]

180. Shim JH, Kim SE, Park JY, Kundu J, Kim SW, Kang SS, Cho DW. Tissue Eng Part A. 2014 DOI: 10.1089/ten.TEA.2013.0513.

181. Hong JM, Kim BJ, Shim JH, Kang KS, Kim KJ, Rhie JW, Cha HJ, Cho DW. Acta Biomater. 2012; 8:2578-2586. [PubMed: 22480947]

182. Cai YZ, Zhang GR, Wang LL, Jiang YZ, Ouyang HW, Zou XH. J Biomed Mater Res A. 2012; 100:1187-1194. [PubMed: 22345081]

183. Mitsak AG, Kemppainen JM, Harris MT, Hollister SJ. Tissue Eng Part A. 2011; 17:1831-1839. [PubMed: 21395465]

184. Jensen J, Rolfing JH, Svend Le DQ, Kristiansen AA, Nygaard JV, Hokland LB, Bendtsen M, Kassem M, Lysdahl H, Bunger CE. J Biomed Mater Res A. 2013 DOI: 10.1002/jbm.a.34970.

185. Jin GZ, Kim TH, Kim JH, Won JE, Yoo SY, Choi SJ, Hyun JK, Kim HW. J Biomed Mater Res A. 2013; 101:1283-1291. [PubMed: 23065721]

186. Carvalho PP, Leonor IB, Smith BJ, Dias IR, Reis RL, Gimble JM, Gomes ME. J Biomed Mater Res A. 2013 DOI: 10.1002/jbm.a.34983.

187. Tuzlakoglu K, Pashkuleva I, Rodrigues MT, Gomes ME, van Lenthe GH, Muller R, Reis RL. J Biomed Mater Res A. 2010; 92:369-377. [PubMed: 19191314]

188. Lu H, Kawazoe N, Kitajima T, Myoken Y, Tomita M, Umezawa A, Chen G, Ito Y. Biomaterials. 2012; 33:6140-6146. [PubMed: 22698726]

189. Schofer MD, Tunnermann L, Kaiser H, Roessler PP, Theisen C, Heverhagen JT, Hering J, Voelker M, Agarwal S, Efe T, Fuchs-Winkelmann S, Paletta JR. J Mater Sci Mater Med. 2012; 23:2227-2233. [PubMed: 22718044]

190. Stoppato M, Stevens HY, Carletti E, Migliaresi C, Motta A, Guldberg RE. Biomaterials. 2013; 34:4573-4581. [PubMed: 23522374]

191. Shui W, Zhang W, Yin L, Nan G, Liao Z, Zhang H, Wang N, Wu N, Chen X, Wen S, He Y, Deng F, Zhang J, Luu HH, Shi LL, Hu Z, Haydon RC, Mok J, He TC. J Biomed Mater Res A. 2013 DOI: 10.1002/jbma.35006. 
192. McFadden TM, Duffy GP, Allen AB, Stevens HY, Schwarzmaier SM, Plesnila N, Murphy JM, Barry FP, Guldberg RE, O’Brien FJ. Acta Biomater. 2013; 9:9303-9316. [PubMed: 23958783]

193. Lin CY, Chang YH, Li KC, Lu CH, Sung LY, Yeh CL, Lin KJ, Huang SF, Yen TC, Hu YC. Biomaterials. 2013; 34:9401-9412. [PubMed: 24016854]

194. Sun Y, Jiang Y, Liu Q, Gao T, Feng JQ, Dechow P, D’Souza RN, Qin C, Liu X. Tissue Eng Part A. 2013; 19:1754-1763. [PubMed: 23469769]

195. Hofmann S, Hilbe M, Fajardo RJ, Hagenmuller H, Nuss K, Arras M, Muller R, von Rechenberg B, Kaplan DL, Merkle HP, Meinel L. Eur J Pharm Biopharm. 2013; 85:119-129. [PubMed: 23958323]

196. Moisenovich MM, Pustovalova O, Shackelford J, Vasiljeva TV, Druzhinina TV, Kamenchuk YA, Guzeev VV, Sokolova OS, Bogush VG, Debabov VG, Kirpichnikov MP, Agapov. Biomaterials. 2012; 33:3887-3898. [PubMed: 22364702]

197. Riccio M, Maraldi T, Pisciotta A, La Sala GB, Ferrari A, Bruzzesi G, Motta A, Migliaresi C, De Pol A. Tissue Eng Part A. 2012; 18:1006-1013. [PubMed: 22166080]

198. Nie H, Ho ML, Wang CK, Wang CH, Fu YC. Biomaterials. 2009; 30:892-901. [PubMed: 19010530]

199. Chesnutt BM, Yuan Y, Buddington K, Haggard WO, Bumgardner JD. Tissue Eng Part A. 2009; 15:2571-2579. [PubMed: 19309240]

200. De la Riva B, Nowak C, Sanchez E, Hernandez A, Schulz-Siegmund M, Pec MK, Delgado A, Evora C. Eur J Pharm Biopharm. 2009; 73:50-58. [PubMed: 19442724]

201. Niu X, Fan Y, Liu X, Li X, Li P, Wang J, Sha Z, Feng Q. Artif Organs. 2011; 35:E119-128. [PubMed: 21658081]

202. Zhang X, Zhu L, Lv H, Cao Y, Liu Y, Xu Y, Ye W, Wang J. J Mater Sci Mater Med. 2012; 23:1941-1949. [PubMed: 22555503]

203. Cai K, Yao K, Yang Z, Qu Y, Li X. J Mater Sci Mater Med. 2007; 18:2017-2024. [PubMed: 17558475]

204. Hou J, Wang J, Cao L, Qian X, Xing W, Lu J, Liu C. Biomed Mater. 2012; 7:035002. [PubMed: 22358865]

205. Abarrategi A, Moreno-Vicente C, Ramos V, Aranaz I, Sanz Casado JV, Lopez-Lacomba JL. Tissue Eng Part A. 2008; 14:1305-1319. [PubMed: 18491953]

206. Haberstroh K, Ritter K, Kuschnierz J, Bormann KH, Kaps C, Carvalho C, Mulhaupt R, Sittinger M, Gellrich NC. J Biomed Mater Res B Appl Biomater. 2010; 93:520-530. [PubMed: 20225216]

207. Planka L, Necas A, Srnec R, Rauser P, Stary D, Jancar J, Amler E, Filova E, Hlucilova J, Kren L, Gal P. Physiol Res. 2009; 58:885-893. [PubMed: 19093735] 

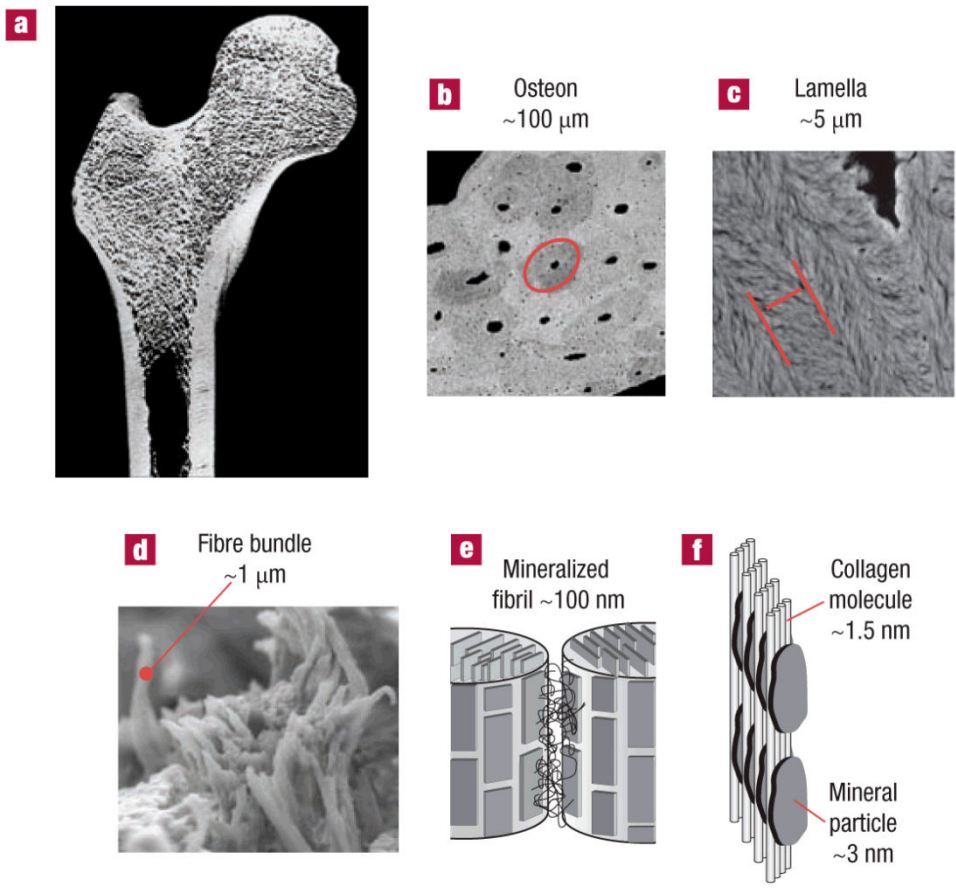

Figure 1.

Electron micrographs and schematic depictions of the hierarchical structure of bone. (a) Human femur bone. (b) Dense cortical bone where the red circle indicates a fundamental unit known as an osteon. (c) Lamella: structural unit composed of parallel collagen sheets. (d) Bundle of mineralized collagen fibrils. (e) Schematic depiction of mineralized fibrils. (f) Arrangement of collagen molecules and apatite crystals within a mineralized collagen fibril. This figure is reprinted with permission from Nature Publishing Group. ${ }^{25}$ 

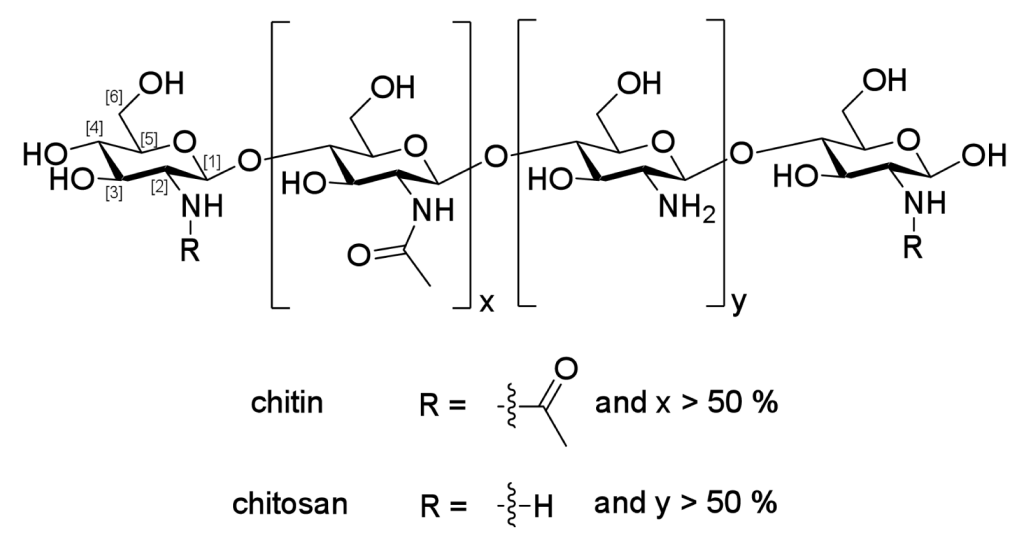

Figure 2.

Chemical structure of chitin and chitosan. 


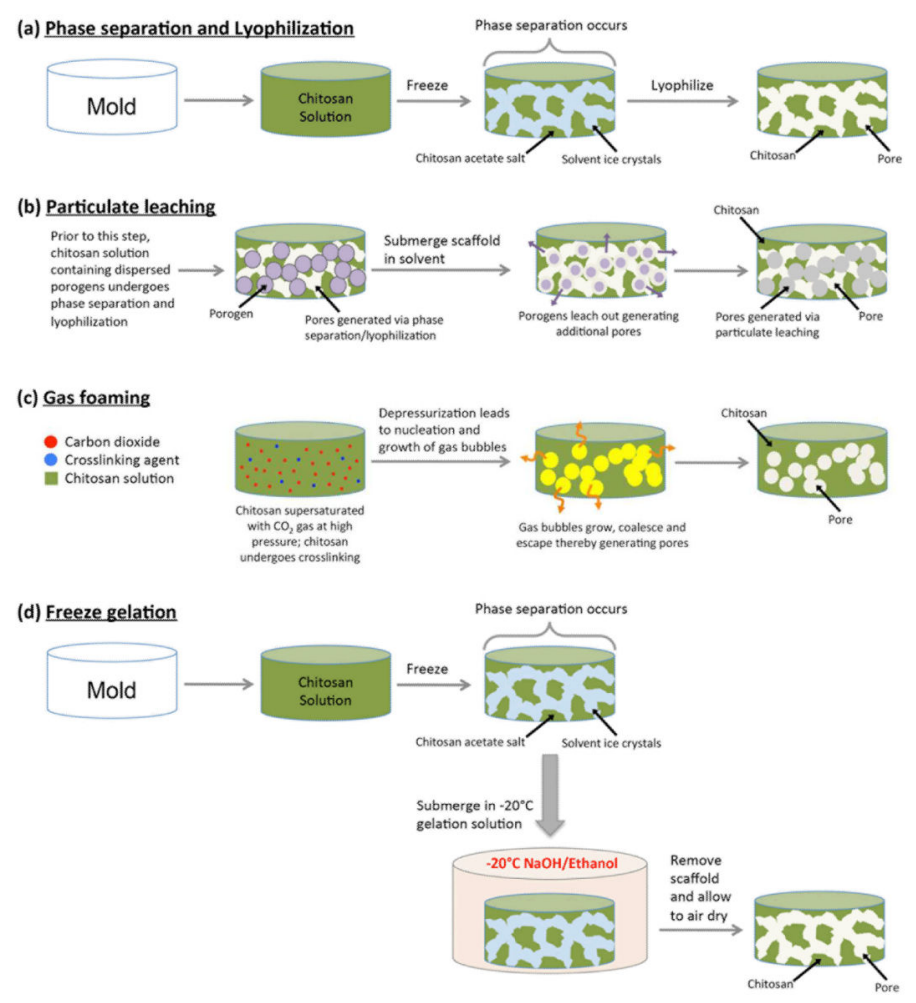

Figure 3.

Schematic representation of four commonly-used chitosan scaffold fabrication methods. (a) Phase separation and lyophilization technique where a chitosan solution is introduced into a mold, frozen to allow for phase separation of acetic acid solvent and chitosan acetate salt and then lyophilized. (b) Particulate leaching technique, which can be combined with phase separation to fabricate chitosan scaffolds. A porogen such as gelatin is mixed with chitosan solution prior to phase separation and lyophilization. The resultant scaffold is submerged in a solvent to allow for porogen leaching resulting in additional porosity. (c) Gas foaming technique where chitosan solution containing a crosslinker (glutaraldehyde) is supersaturated with carbon dioxide at high pressure while also undergoing crosslinking. When the system is depressurized, thermodynamic instability leads to nucleation and growth of gas bubbles. Gas bubbles grow and/or coalesce and escape the polymer solution thereby generating pores. (d) Freeze gelation technique, which initially involves phase separation due to freezing. The scaffold is placed in a gelation solution of sodium hydroxide and ethanol below the chitosan freezing temperature. Following gelation, the scaffold is air-dried to remove residual liquid. 

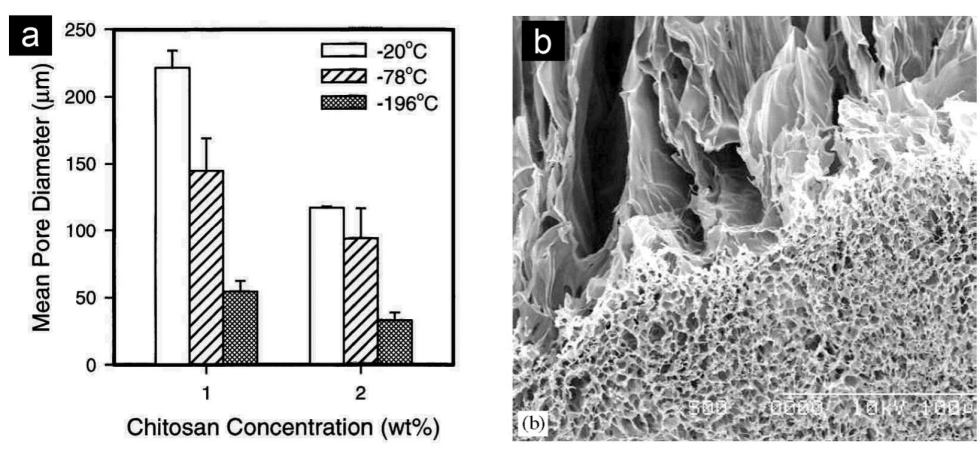

Figure 4.

Structural properties of chitosan scaffolds prepared using the phase separation method. (a) Effect of freezing temperature and chitosan concentration on mean pore diameter of chitosan scaffolds. (b) SEM micrograph showing the resultant structure of a radial thermal gradient where two levels of porosity are present due to surface cooling at solution-glass mold interface. This figure is reprinted with permission from Elsevier. ${ }^{41}$ 

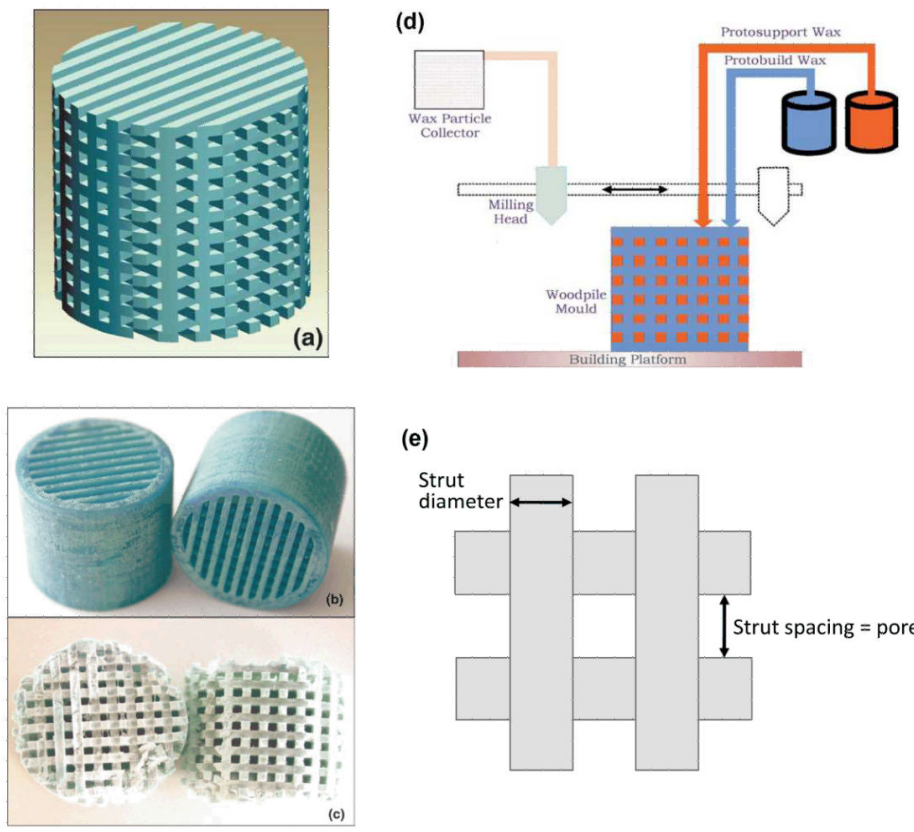

(e)

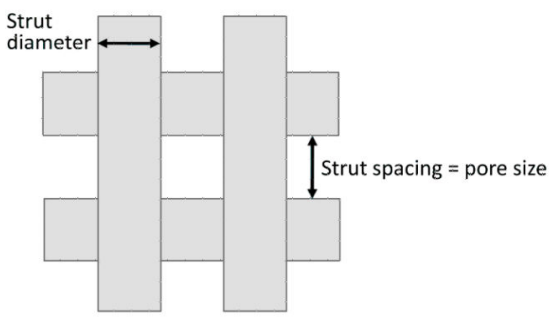

Figure 5.

Illustration of rapid prototyping in generating chitosan scaffolds where an inverse wax mold is deposited using computer-aided manufacturing technology and the mold used to cast scaffolds. (a) CAD design of negative wax mold with perpendicular struts. (b) As-fabricated wax mold with outer wall to hold slurry during casting. (c) Chitosan-hydroxyapatite scaffold following casting and freeze gelation. (d) Schematic presentation of the 3D printer used to deposit wax molds. (e) Schematic depiction of scaffold $x-y$ plane showing how the strut spacing defines the pore size. Figure $5(\mathrm{a}-\mathrm{d})$ is adapted and reprinted with permission. ${ }^{87}$ 

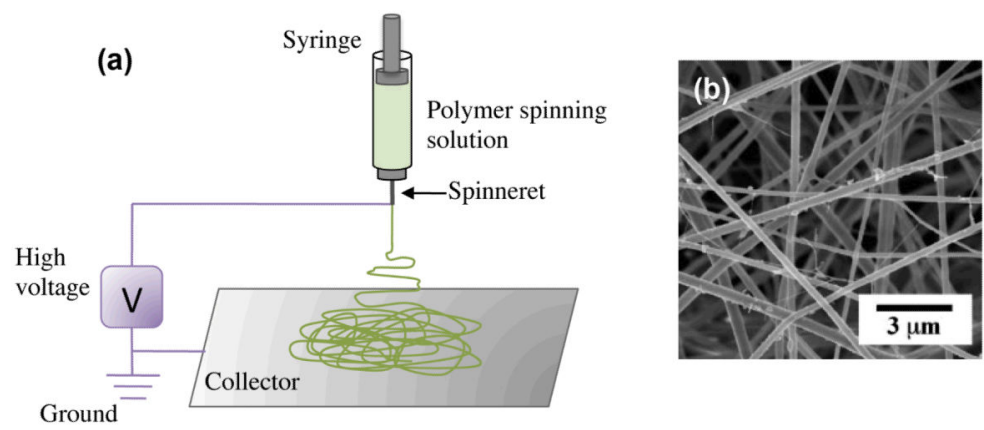

Figure 6.

Chitosan nanofibers produced by electrospinning. (a) Illustration of a typical electrospinning system for producing polymer nanofibers. (b) SEM image of pure chitosan nanofibers

fabricated by electrospinning. Figure 3(b) is adapted and reprinted with permission. ${ }^{104}$ 

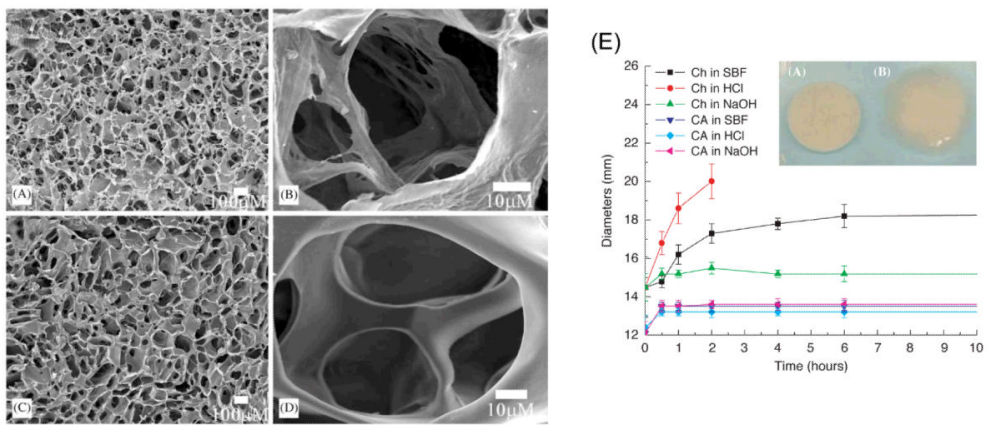

Figure 7.

Chitosan and chitosan-alginate scaffolds produced by phase separation where chitosan and alginate form a polyelectrolyte complex. SEM micrographs of chitosan scaffold pore structure at (a) low and (b) high magnification. SEM micrograph of chitosan-alginate scaffold pore structure at (c) low and (d) high magnification. (e) Changes in scaffold diameter for chitosan-alginate (CA, inset left) and chitosan ( $\mathrm{Ch}$, inset right) upon hydration with $1 \mathrm{~N} \mathrm{HCl}, 1 \mathrm{~N} \mathrm{NaOH}$ and $\mathrm{SBF}$ solutions. This figure is reprinted with permission from Elsevier. ${ }^{125}$ 

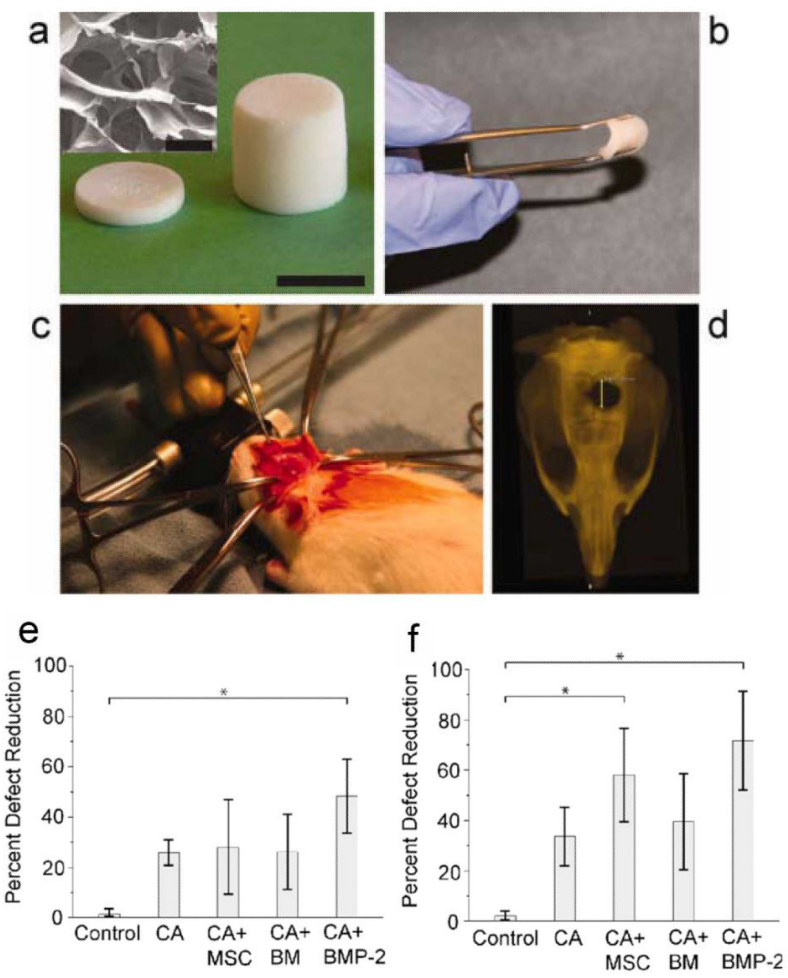

Figure 8.

Chitosan-alginate scaffolds evaluated for in vivo bone regeneration using a critical size rat calvarial defect. (a) As-fabricated chitosan-alginate scaffold (right) that is sectioned to produce discs for implantation (scale bar: $10 \mathrm{~mm}$ ); Inset: SEM micrograph showing scaffold microstructure (scale bar: $100 \mu \mathrm{m}$ ). (b) Scaffolds exhibit flexibility and handleabiliy required for clinical application. (c) Rat critical size cranial defect model as seen during the surgical procedure. (d) Micro-CT imaging of rat cranium showing defect (line is $5 \mathrm{~mm}$ ). Percent defect reduction at (e) 4 weeks and (f) 16 weeks. This figure is reprinted with permission from John Wiley and Sons. 158 


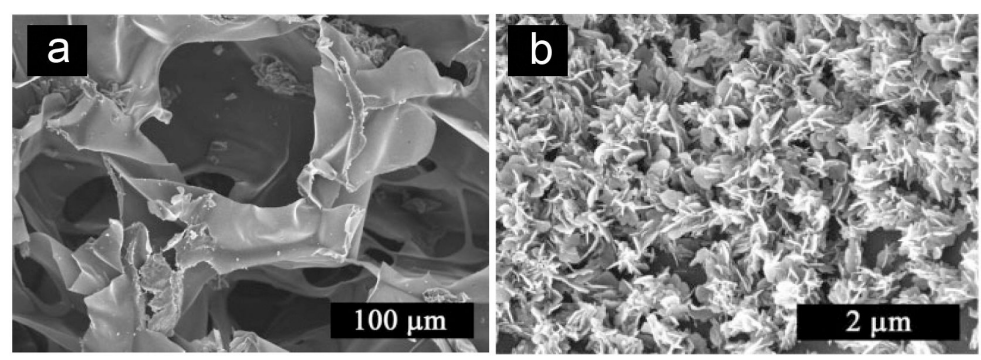

C

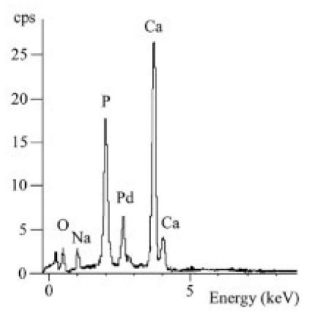

d

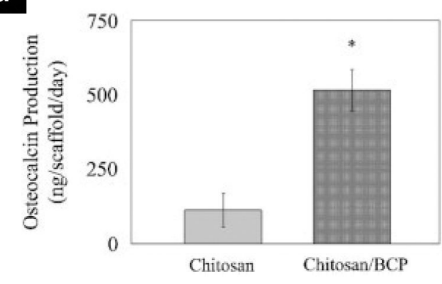

Figure 9.

Composite chitosan scaffolds containing biphasic calcium phosphate microparticles. (a) SEM micrograph of chitosan/BCP scaffolds with $80 \%$ total porosity and mean pore size of $100 \mu \mathrm{m}$. (b) SEM micrograph of apatite layer formed on scaffold surface after incubation in cell culture medium. (c) EDX of the apatite layer showing a Ca:P ratio of 1.58 for the mineral, which is similar to stoichiometric Ca:P ratio of bone mineral (1.67). (d) Osteocalcin production is significantly higher in chitosan/BCP scaffolds. This figure is reprinted with permission from John Wiley and Sons. ${ }^{164}$ 

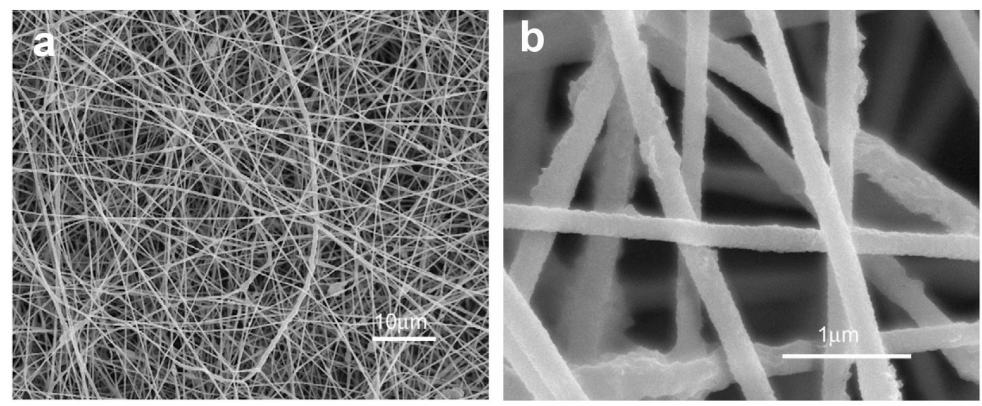

Figure 10.

Field emission scanning electron micrographs of hydroxyapatite-chitosan nanocomposite fibers doped with $10 \mathrm{wt} \%$ ultrahigh molecular weight poly(ethylene oxide) as a fiberforming agent. (a) Low magnification image showing nanofiber uniformity and (b) high magnification image detailing that some protrusions are visible due to HA nanoparticles. This figure is reprinted with permission from Elsevier. ${ }^{141}$ 

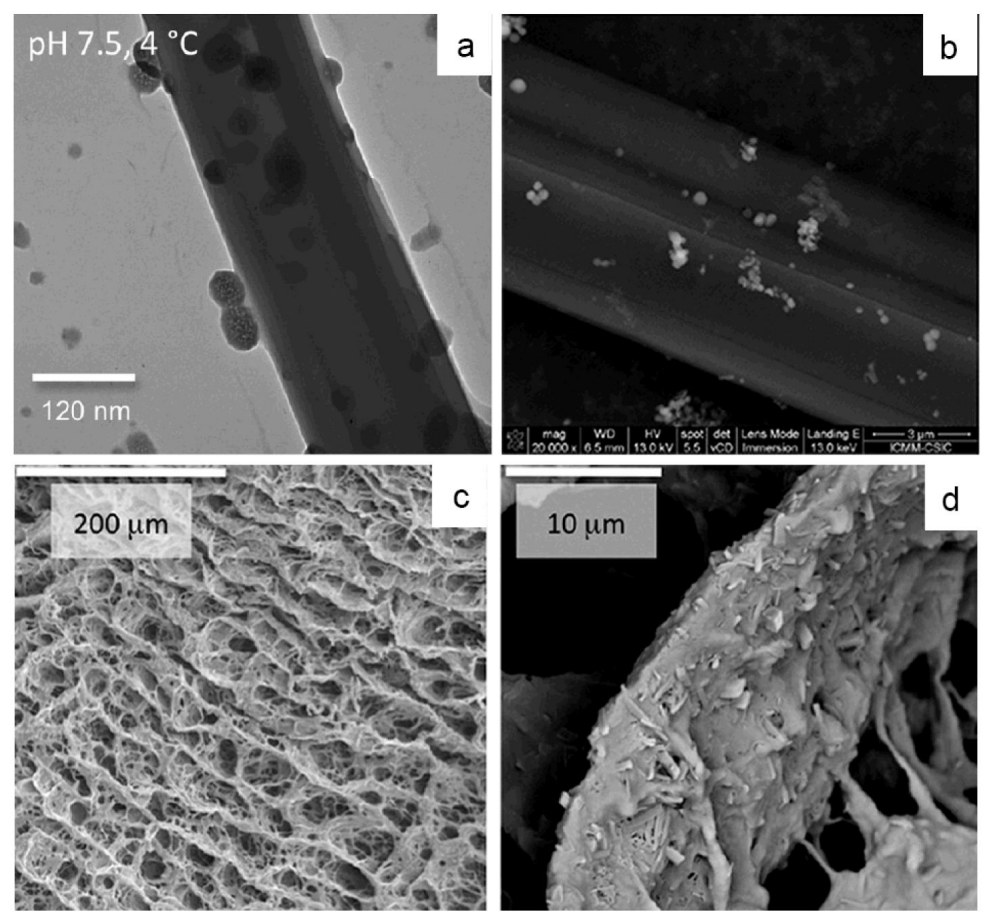

Figure 11.

Multifunctional porous chitosan scaffolds containing ciprofloxacin crystals and amorphous calcium phosphate aggregates. (a) TEM micrograph and (b) SEM micrograph showing needle-like ciprofloxacin crystals with granular, amorphous calcium phosphate precipitates on crystal surfaces. (c) Low magnification SEM micrograph showing the porous structure of the chitosan scaffold. (d) High magnificent SEM micrograph showing a scaffold pore wall with integrated ciprofloxacin crystals. This figure is reprinted with permission. ${ }^{171}$ Copyright 2014 American Chemical Society. 


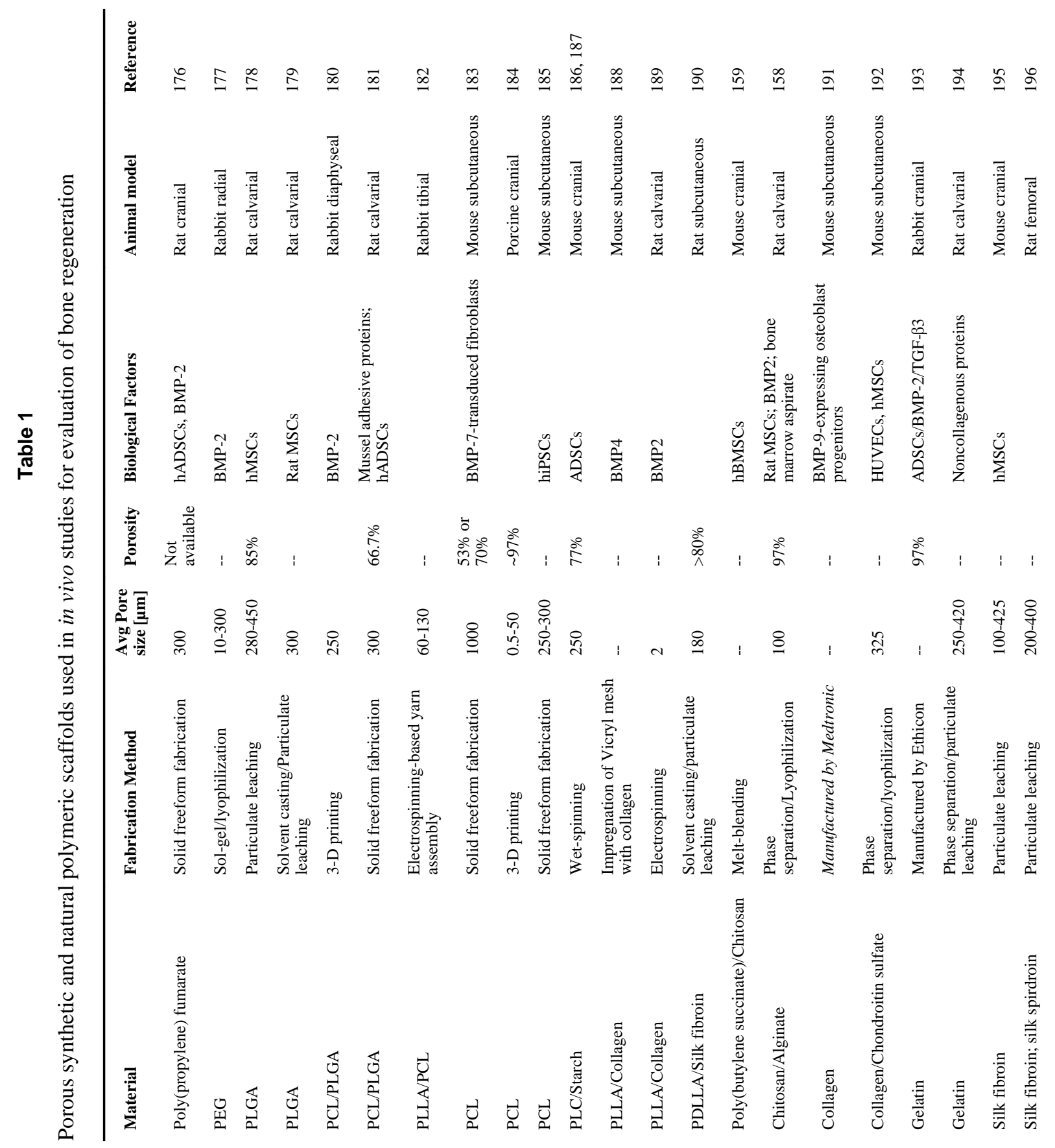




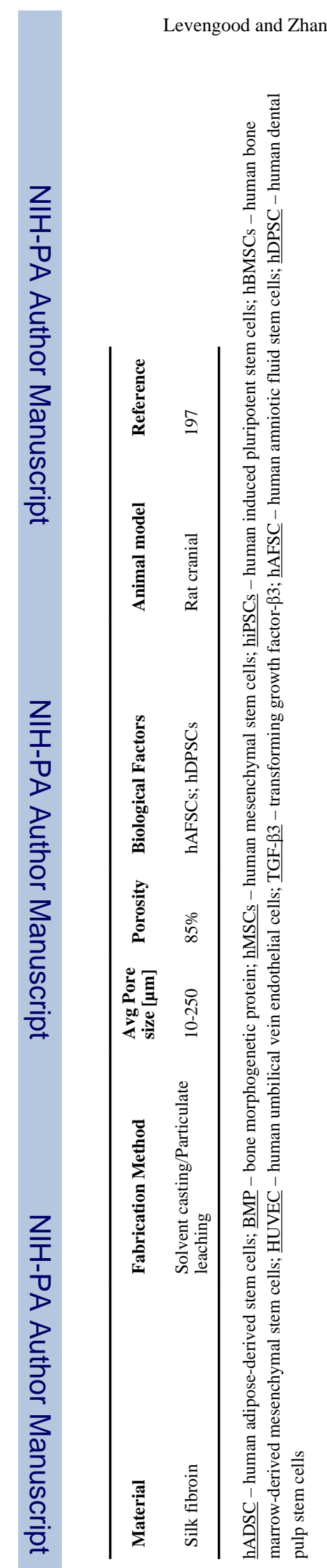

Page 44 


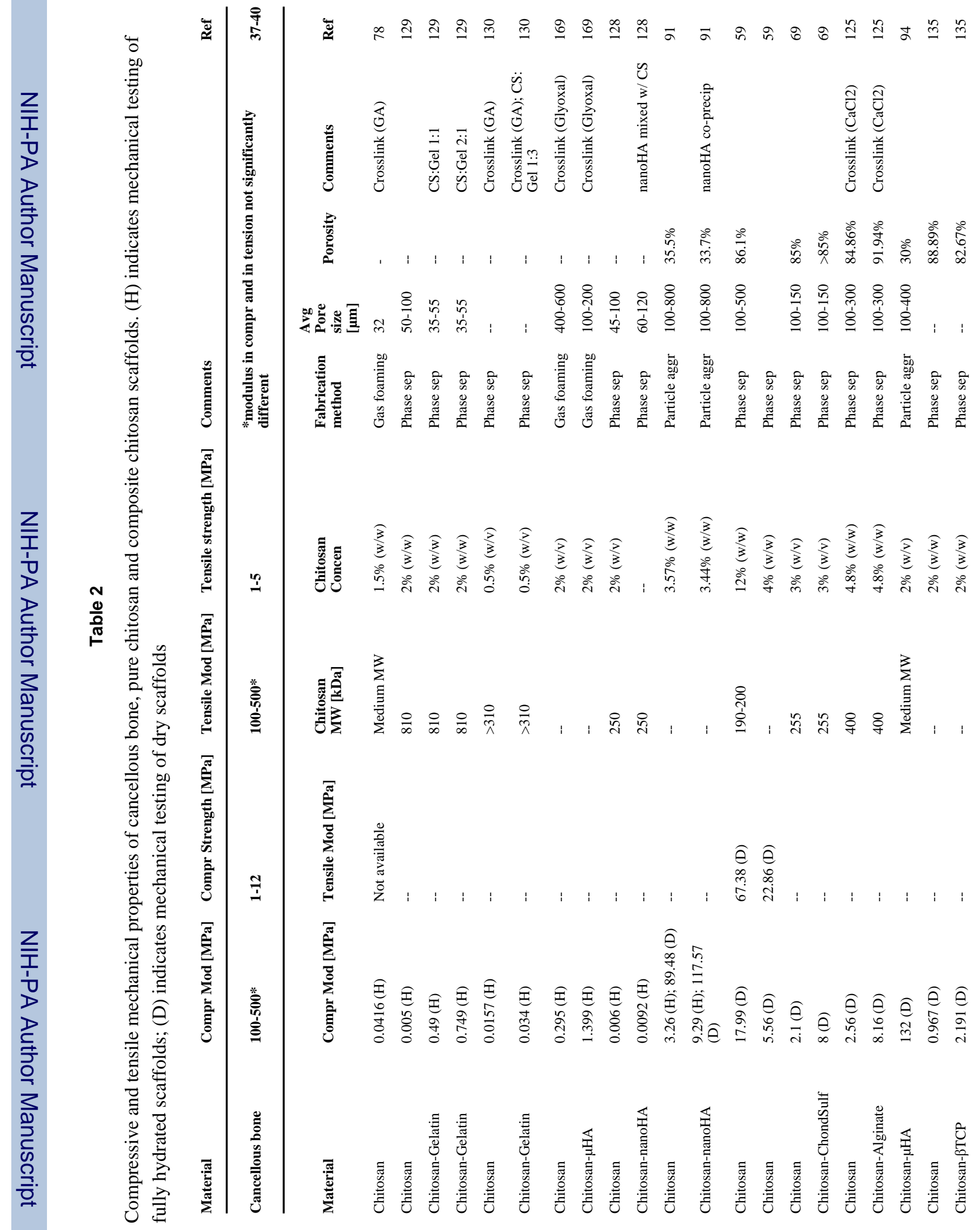




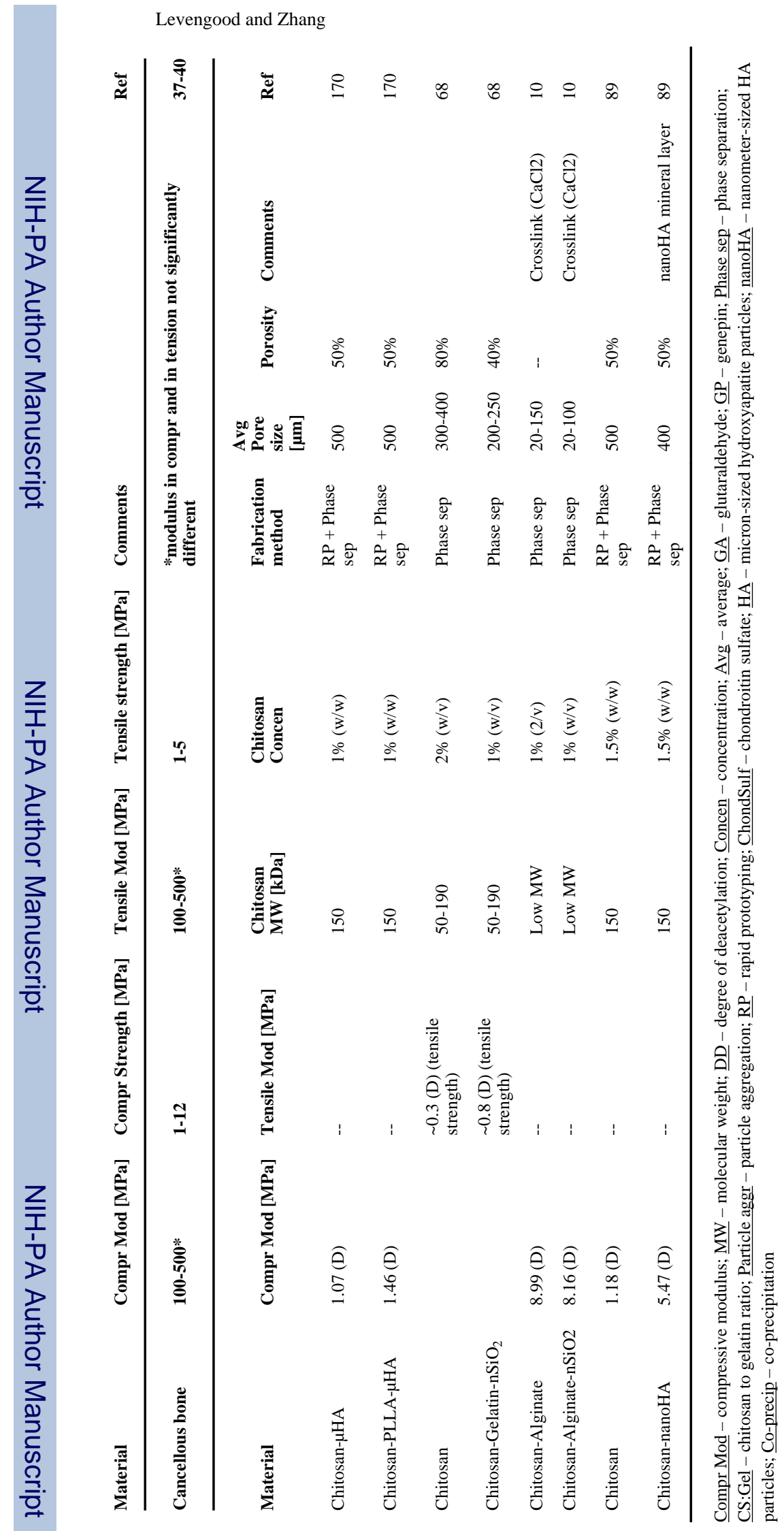

J Mater Chem B Mater Biol Med. Author manuscript; available in PMC 2015 June 07. 
Table 3

In vivo studies evaluating chitosan-based bone scaffolds

\begin{tabular}{lll}
\hline Species & Defect site & Reference \\
Mouse & Tibia & 198 \\
Mouse & Calvarial & $152,158,159$ \\
Rat & Calvarial & 46,199 \\
Rat & Tibia & 160 \\
Rat & Femur & 200 \\
Rabbit & Femoral condyle & 201,202 \\
Rabbit & Radius & 203,204 \\
Rabbit & Fibula & 161 \\
Rabbit & Cranial & 205 \\
Dog & Mandible & 162,163 \\
Sheep & Calvarial & 206 \\
Mini-pig & Femur & 207 \\
\hline
\end{tabular}

